\title{
ALIENAZIONI A TITOLO GRATUITO IN DOCUMENTI DEI SECOLI XI-XII
}

\section{ALIENATIONS WITHOUT CONSIDERATION IN THE CHARTAE OF THE XI AND XII CENTURIES}

\author{
Marialuisa Bottazzi \\ CERM (Centro Europeo di Ricerche Medievali) di Trieste
}

Abstract English: Only a small number of chartae drawn up since the early Middle Ages can be said to have had a parallel life to their usual and pre-eminent legal or notarial destination. This parallel life follows the choice, mainly by legatees, to engrave onto stone even just part of the textual content of the parchments. The purpose of this decision was to notify, publicise, and perpetuate, generally pro redemptione animae, the memory of what wealthy benefactors had arranged, initially in favour of monastic institutions and, later, also in favour of both religious and secular charitable institutions. Most of these scarce inscriptions, which we classify as 'chartae lapidariae' - due to their close relationship to notarial chartae, from which they derive - have been produced in Italy since the end of the tenth century, to be regularly exhibited inside or nearby sacred places. In most cases, we speak of inscriptions containing inter vivos or mortis causa testamentary acts or donations; less often, their enacting and probative content refers to papal bulls, decrees or royal or imperial orders. In both instances, we are faced with engraved documents which are irrefutable from a legislative point of view. However, the customary loss of the notarial document from which each charter derives and the lack of one or more of its essential elements, such as the datatio - probably due to the charter's generally accepted function, since Roman times, as 'regesta' of the original document - means that the chartae lapidariae can hardly be considered 'documents in the proper sense', but only separate epigraphic 'monuments'. Therefore, they are particularly interesting to analyse merely for their historical significance. Despite this, due to all the elements considered up to now - which can be summarised as the difficulty of demonstrating the reliability of the contents engraved onto stone, given that it is impossible to reconstruct the intimate epigraphic/documentary use of the lapidary chartae in relation to their lost notarial original - the work of Pietro Sella, Cinzio Violante, and Ottavio Banti in the past century has shed an important light on this type of documents. Nonetheless, even today, the chartae lapidariae receive little consideration. However, in the face of documentary scarcity - as is the case for Milan - they are effective in defining the role of the laity, both within the ecclesial space and in society. They are also useful in the study of charitable institutions - religious as well as secular - and of the ruling classes of Italy, especially of Milan, during the eleventh century. Therefore, despite the fact that the diplomatic significance, itself limiting the legal reliability of the chartae lapidariae, seems to have often prevailed over the historical interest, albeit of an analytical nature of the contents

* Italian Review of Legal History, 7 (2021), n. 17, pagg. 595-643

* https://riviste.unimi.it/index.php/irlh/index

* ISSN 2464-8914 - DOI 10.54103/2464-8914/16899. Articolo pubblicato sotto Licenza CC-BY. 
of the chartae, this work aims at drawing the attention to three important and exceptional examples produced during the last twenty years of the eleventh century in Viterbo, Milan and Collescipoli.

Keywords: inscriptions; wills; grants; Middles Ages; notaries

Abstract Italiano: Solo un numero esiguo di chartae rogate sin dall'alto medioevo si può dire abbia avuto una vita parallela alla consueta e preminente destinazione giuridica o amministrativa notarile grazie alla scelta d'incidere su pietra, il più delle volte da parte dei legatari, anche una sola parte del contenuto testuale pergamenaceo al fine di notificare, di pubblicizzare e di perpetuare, generalmente pro redemptione animae, la memoria di quanto veniva disposto da agiati benefattori a favore, in un primo tempo delle istituzioni monastiche ed ecclesiastiche e più tardi anche gli enti assistenziali, sia religiosi sia laici. La maggior parte di queste non numerose iscrizioni, che classifichiamo come chartae lapidariae, per lo stretto rapporto con le chartae notarili da cui derivano, sono state per la maggior parte prodotte in Italia sin dalla fine del secolo $X$ per essere esposte con una certa frequenza nei luoghi sacri o molto attigui degli stessi. Nella maggior parte dei casi si parla di iscrizioni contenenti atti testamentari o di donazione inter vivos o mortis causa; meno frequentemente il loro tenore dispositivo e probatorio riconduce a bolle papali, decreti o a diplomi regi o imperiali. In ogni caso, siamo sempre di fronte a documenti incisi indiscutibili secondo qualsiasi piano giuridico ma che, per la consuetudinaria perdita del documento notarile da cui derivano e per la facile mancanza anche di uno degli elementi essenziali della charta, per esempio, della datatio, probabilmente per la funzione generalmente assunta, sin dall'impiego romano, di "regesto" dell'atto originale, per la mancanza, si diceva di alcuni elementi essenziale del documento notarile difficilmente possono essere considerati "documenti in senso proprio", ma solo dei "monumenti" epigrafici a sé stanti, quindi particolarmente interessanti da analizzare solo per il loro "peso" storico. Malgrado ciò, per tutti gli elementi fin qui considerati e riassumibili nella difficoltà di dimostrare l'attendibilità dei contenuti incisi su pietra data l'impossibilità di ricostruire l'intimo impiego epigrafico/documentario intrinseco delle carte lapidarie con il loro originale notarile perduto, qualche importante attenzione verso questo tipo di documentazione è comunque giunta nel secolo scorso grazie ai lavori di Pietro Sella, di Cinzio Violante e di Ottavio Banti. Ciò nonostante, ancora oggi, le chartae lapidariae risultano poco considerate sebbene dinanzi a una rarefazione documentaria, per esempio nel caso di Milano, risultino efficaci per definire il ruolo dei laici sia entro lo spazio ecclesiale sia nella società; sia nello studio degli enti assistenziali, sia religiosi sia laici, come dei ceti dominanti dell'Italia e in special modo di Milano, del secolo XI. Se, dunque sull'interesse storico, seppur analitico dei contenuti della chartae lapidariae, sembra aver spesso prevalso il "peso" diplomatistico, che pone dei limiti all'attendibilità giuridica delle carte lapidarie, con questo lavoro si vuol richiamare l'attenzione su tre casi importanti e eccezionali prodotti nell'ultimo ventennio del secolo XI a Viterbo, a Milano e a Collescipoli.

Parole chiave: iscrizioni; testamenti; donazioni; medioevo; notai

Sommario: 1. Introduzione. - 2. Le "chartae" di S. Maria Nova di Viterbo. - 2.1. La pergamena. - 2.2. La "charta lapidaria". - 3. Carità e benevolenza laica; le "chartae" per l'Ospedale di S. Simpliciano di Milano. - 3.1. La charta lapidaria di Lanfranco e Fraxia e le due 
chartae notarili. - 3.2. La prima carta di Lanfranco. - 3.3. Le parallele carte di Lanfranco e Fraxia e la charta lapidaria. - 4. Le "chartae lapidariae" di Collescipoli. - 4.1. "Contractus» e «breve recordationis» lapidei. - 4.2. II "contractus", ovvero la "charta donationis". -4.3. La stipulazione, ovvero il "breve". - 5. Conclusioni guardando a un'auspicata "libertas ecclesiae".

\section{Introduzione}

Solo un numero esiguo di chartae rogate sin dall'alto medioevo si può dire abbia avuto una vita parallela alla consueta e preminente destinazione giuridica o amministrativa notarile grazie alla scelta d'incidere su pietra, il più delle volte da parte dei destinatari, anche una sola parte del contenuto testuale pergamenaceo al fine di notificare, di pubblicizzare e di perpetuare, generalmente pro redemptione animae, la memoria di quanto veniva disposto da agiati benefattori a favore, in un primo tempo delle istituzioni monastiche ed ecclesiastiche e più tardi anche dagli enti assistenziali, sia religiosi sia laici. La maggior parte di queste non numerose iscrizioni, che classifichiamo come chartae lapidariae per lo stretto rapporto con le chartae notarili da cui derivano, sono state per la maggior parte prodotte in Italia sin dalla fine del secolo X per essere esposte con una certa frequenza nei luoghi sacri o molto attigui degli stessi ${ }^{1}$. Nella maggior parte dei casi si parla di iscrizioni contenenti atti testamentari o di donazione inter vivos o mortis causa; meno frequentemente il loro tenore riconduce a bolle papali, decreti o a diplomi regi o imperiali. In ogni caso, siamo sempre di fronte a documenti incisi indiscutibili secondo qualsiasi piano giuridico ma che, per la consueta perdita del documento notarile da cui derivano e per la facile mancanza anche di uno degli elementi essenziali della charta originale, per esempio, della datatio, per la probabile funzione generalmente assunta, sin dall'impiego romano, di "regesto" dell'atto originale, difficilmente possono essere considerati "documenti in senso proprio", ma solo dei "monumenti" epigrafici a sé stanti, quindi particolarmente interessanti da analizzare solo per il loro "peso" storico. Malgrado ciò, per tutti gli elementi fin qui considerati e riassumibili nella difficoltà di dimostrare l'attendibilità dei contenuti incisi su pietra data l'impossibilità di ricostruire, spesso, l'intimo impiego epigrafico/documentario intrinseco delle carte lapidarie con il loro originale notarile perduto, qualche importante attenzione verso questo tipo di documentazione è comunque giunta nel secolo scorso grazie ai lavori di Pietro Sella, di Cinzio Violante e di Ottavio Banti²; ciò nonostante, ancora oggi, le chartae lapidariae risultano poco considerate sebbene dinanzi a una rarefazione do-

\footnotetext{
${ }^{1}$ Molto anticipato è il caso napoletano della carta lapidaria di Cuma, databile in modo approssimativo al VII secolo, contenente un contratto di compravendita. La trascrizione della carta lapidaria è stata editata da Minieri Riccio, 1846 e da Capasso, 2008, pp. 292-293. ${ }^{2}$ Sella, 1928, pp. 406-421; Violante, 1962, pp. 147-168; Id., 1962, pp. 643-745; Banti, 1992, pp. 229-242.
} 
cumentaria risultino spesso fondamentali per definire il ruolo dei laici sia entro lo spazio ecclesiale sia nella società urbana; sia nello studio degli enti assistenziali, sia religiosi sia laici, come dei ceti dominanti dell'Italia e in special modo di Milano, del secolo XI. Se, dunque, sull'interesse storico, seppur analitico dei contenuti della chartae lapidariae, sembra aver spesso prevalso il "peso" diplomatistico, che pone dei limiti all'attendibilità giuridica delle carte lapidarie", con questo lavoro si vuol richiamare l'attenzione su tre casi importanti ed eccezionali rogati e incisi nell'arco dell'ultimo ventennio del secolo XI a Viterbo, a Milano e a Collescipoli a fronte di fondazioni di nuovi enti promossi da benefattori laici.

La partecipazione dei saeculares alla vita religiosa, sempre più limitata alla sola partecipazione economica nella fondazione di monasteri ed enti assistenziali è documentata significativamente dai molti lasciti custoditi negli archivi.

L'incoraggiamento vescovile ai laici per un'assistenza agli infermi e ai poveri che era stata inizialmente offerta dai monasteri, spesso fondati e sostenuti dai signori feudali dalle capacità economiche e progettuali dinastiche ben conosciute, già prima della metà del secolo $\mathrm{XI}$, venne assimilata dalle nuove élites cittadine laiche ormai in grado di esprimere una nuova coscienza e consapevolezza sociale grazie anche a più importanti capacità economiche, esito dell'espansione economica e del processo d'inurbamento documentato, in Italia, tra la fine del $\mathrm{X}$ e gli inizi dell'XI secolo. Gli enti ospedalieri inizialmente affiancati alle istituzioni monastiche, divennero i nuovi centri di aggregazioni dinastico-famigliari come della partecipazione laica alla vita religiosa testimoniata dal numero importantissimo di iudicati e chartae donationis traditi con permeante intento pio ${ }^{4}$. Nell'XI secolo a donare sono, dunque, le famiglie appartenenti alle élites certamente non nobili, ma benestanti dei negoziatores, degli argentarii e degli artigiani in genere, inseriti socialmente e ricchi di contatti utili a dar vita a nuovi luoghi destinati all'accoglienza e all'assistenza ospedaliera velocemente organizzata ${ }^{5}$. Attorno, infatti, a quelle ricche famiglie, che agivano ad imitazione delle dinastie aristocratiche dei secoli precedenti, si organizzava il "capitale" umano del secolo XI "preso", dalla stessa concezione cristiana dei facoltosi donatori di portio pro anima che, in cerca di Cristo tra i miserabili, oltre che alla carità delle proprie opere, ricorrevano anche a un complesso sistema di istituti giuridici per raggiungere l'unico fine che ogni uomo si sentiva di dover raggiungere nell'aldilà: la salvezza della propria anima e quella di quella dei propri cari ${ }^{6}$. Le nuove fondazioni ospedaliere e il sistema di assistenza che veniva organizzato, offrivano ospitalità e servizio a "poveri" e "pellegrini", inseriti in uno spazio istituzionale e gerarchico che poteva essere coordinato dalle istituzioni ecclesiastiche il più delle volte escluse,

\footnotetext{
${ }^{3}$ Campana, 1984, pp. 363-403.

${ }^{4}$ Sergi, 1994, p. IX.

${ }^{5}$ lacomelli, 1997, pp. 79-95.

${ }^{6}$ Vismara, 1988, pp. 16-18; Cammarosano, 2001, pp. 376-378.
} 
invece, dalla gestione dei patrimoni istituiti all'atto della fondazione; questo è, almeno, ciò che emerge dalla lettura delle testimonianze documentarie epigrafiche e notarili dei casi presi qui in considerazione, che saranno proposti secondo il loro ordine di datazione a tutti gli effetti molto omogenea perché compresa per tutti nell'ultimo ventennio del secolo $\mathrm{XI}$, che ricordo essersi contraddistinto, altrettanto omogeneamente in Italia, per le grandi incertezze sociali e politiche spesso sfociate in atteggiamenti forti contro i "pagani" e in durissimi contrasti tra i milites e i populares ${ }^{8}$.

\section{Le chartae di S. Maria Nova di Viterbo}

La pergamena n. 2 della Biblioteca Comunale degli Ardenti di Viterbo, contenente il brevilegium rogato il 13 dicembre del 1080 per S. Maria Nova, è uno dei riferimenti storici più importanti per la storia sociale e religiosa viterbese segnata in quel periodo dalle diverse situazioni che si stavano concentrando sulla Tuscia. Nello stesso anno in cui venne rogato quel privilegio, che sancì il passaggio della chiesa fondata e governata dal prete Biterbo e dai laici della sua famiglia alla Chiesa, elevando lo stesso edificio sacro a prima canonica viterbese e formalizzando la presenza del vicino ospedale, la marchesa Matilde di Canossa, secondo il Chronicon Cassinese, aveva già disposto il passaggio di parte dei beni, sembra, allodiali, del marchesato alla Chiesa con effetto post mortem $^{9}$ : papa Gregorio VII era ormai ad un passo dal suo finale esilio salernitano dopo aver segnato indelebilmente l'assetto ecclesiastico e cambiato i rapporti di forza del potere temporale rispetto a quello secolare, mentre in quel quadro di grande fluidità politica e istituzionale anche la figura del vescovo di Toscanella Giselberto, che sappiamo già presente al placito del 1080 tenuto dalla marchesa di Tuscia a Corneto, dalla documentazione viterbese sembra vigilare anche su altre chiese oltre su quella del prete Biterbo, poi elevate come S. Maria Nova a canonica entro I'XI secolo e soprattutto entro il suo mandato vescovile. Dopo la chiesa del prete Biterbo e dei suoi parenti, infatti, anche quella di S. Michele Arcangelo e quella di S. Sisto iniziarono a indirizzare il clero a una vita canonicale ${ }^{10}$, ma solo l'atto per S. Maria Nova, per probabile scelta dei suoi patrocinatori, avrebbe avuto anche una sua dimensione epigrafica, scolpita sulle tre facce di un cippo di marmo di peperino rosso ancora oggi posto a cornu epistolae entro la stessa chiesa da ritenersi una della

\footnotetext{
${ }^{7}$ Cammarosano, 2001/b, pp. 1-6. Non è questo il caso dell'ospedale di Peragine studiato da Paolo Cammarosano. Sorto sulla via Francigena, presso Porta Camollia a Siena, da un patronato non certo aristocratico l'ospedale passò poi sotto la giurisdizione del monastero di San Michele di Passignano che demandò l'istituzione ospedaliera ai preti Bonfiglio e Pietro.

${ }^{8}$ Cammarosano, 2001/a, pp. 226-314.

${ }^{9}$ Signorelli, 1907, I, p. 103.

${ }^{10}$ Signorelli, 1907, pp. 101-114.
} 
chartae lapidariae più rappresentative della sua tipologia prodotta in Italia ${ }^{11}$.

\subsection{La pergamena}

Conformemente all'andamento osservato da Fernando De Lasala e da Paulius Rabikauskas per i territori della Cristianità più prossima a Roma ${ }^{12}$, il 13 dicembre 1080 , nello stilare l'atto con cui il prete Biterbo avrebbe donato, assieme al fratello Leone, alla madre Sassa e alla moglie di Leone Carabona, la chiesa di S. Maria Nova di Viterbo, fino a quel momento di loro proprietà, Anastasio, infelix sacerdos e scriptor, trovò più conveniente redigere un documento che avrebbe rimandato al brevilegium, ovvero a un atto particolare (privi-legium) indicato "dai riformatori" ecclesiastici dell'XI secolo come in uso nel caso in cui, trattando di istituzioni ecclesiastiche era importante prevedere e ostacolare tutte le possibili intromissioni da parte del potere secolare della $l e x^{13}$. A questo proposito fu, allora, importante per Anastasio, lo scriptor dell'atto, che non accenna in nessun punto del documento a una sua qualifica notarile preferendo evidenziare il proprio importante compito dello "scrivere" il documento ${ }^{14}$, ricordare immediatamente che ciò che si redigeva, il brevilegium, veniva fatto in presenza dell'autorità ecclesiastica in quel momento più alta, del territorio, il vescovo di Toscanella Giselbertus. Da partecipe alla stesura del documento il vescovo avrebbe convalidato quanto veniva fissato nel libellum, l'altro modo in cui viene definito più volte il documento, che veniva "roborat(um) coram testium, stipulatione subnixa", dinanzi a un largo numero di testimoni presenti, ma non sottoscrittori, che superarono i richiesti cinque o sette testimoni previsti dal diritto giustineaneo per gli atti di liberalità mortis causa ${ }^{15}$. La chiesa posta nel borgo a est del castello sulla piazza del mercato venne, quindi, offerta, donata, concessa al clero viterbese, ma nello stesso tempo si assistette anche all'istituzione della canonica da organizzare negli spazi già destinati e venne formalizzato istituzionalmente l'ospedale per $\mathrm{i}$ pellegrini e per i mendicanti già in essere rispettando le formalità notarili degli atti mortis causa. La charta, infatti, nella sua iniziale, lunghissima, dispositio ricca di molti, ampi, riferimenti ai testi evangelici di chiaro impiego chiericale, che presero anche molto spazio dell'arenga, dispose che Domino adiuvante la chiesa e tutti i suoi annessi fosse donata pro redemptione anime del prete Biterbo degli altri donatori, dei loro genitori, di tutti i fedeli cristiani e "parentorum nostrorum,

\footnotetext{
${ }^{11}$ Charta lapidaria della donazione per di S. Maria Nova a. 1080; cfr. appendice documentaria n. 2.

${ }^{12}$ De Lasala, Rabikauskas, 2003, pp. 194-195.

13 Ibidem.

${ }^{14}$ Liva, 1979, pp. 6-9. Osservando le carte milanesi rogate tra il secolo IX e il secolo X Alberto Liva ha osservato una presenza importante di rogatari d'ambito ecclesiastico che, in certi casi, preferirono evidenziare la loro attività di scrittore piuttosto che quella più corporativa di notarius.

${ }^{15}$ Bartoli Langeli, 2006, p. 45.
} 
ut hic et in futuro seculo semper mercedem adcrescat", a favore di tutti gli ordini clericali, compresi i minori, e ai fedeli laici servi dei servi di Dio, completa delle sue strutture e dei numerosissimi beni e proprietà, citati come le ampie clausole di pertinenza prevedevano, annessi alla chiesa in modo che entro i suoi spazi avesse luogo la vita comune del clero formalizzata dallo stesso atto di donazione espresso da Biterbo e dalla sua famiglia. L'atto unilaterale, di fatto, una concessione speciale dal carattere molto "ibrido", comunque un privilegium, come troviamo scritto nella completio dello scriptor Anastasio, che il vescovo Giselberto confermò, come si diceva, propria manu, ricalcò, secondo Paolo Frezza, la prassi già osservata negli atti lucchesi e nel cartulario di Farfa per la quale un vescovo, comunque a conoscenza delle fonti giuridiche romane, poteva regolare i negozi patrimoniali di un chierico, nonostante fosse chiaro sin dal principio che non si trattava di un atto di comune interesse tra ecclesiastici, ma del trasferimento della proprietà di alcuni possedimenti, nel caso di Viterbo, di Biterbo e della sua famiglia alla Chiesa ${ }^{16}$. Secondo la charta i beni, per il volere dei benefattori, vennero dunque donati, traditi, elargiti, concessi ed offerti pro amore Dei onnipotentis davanti alla chiesa di San Silvestro, centro oramai importante di sosta per pellegrinaggio lungo la via Francigena, dunque verso Roma. L'ospedale sarebbe, quindi, stato retto a beneficio di "vivis et defunctis qui hunc hospitalem ad susceptionem peregrinorum vel pauperum infirmorum, ut ibi teneantur infirmi hac sospes resilient sanato constituerunt vel ordinaverunt" rispettando quelle che erano "le regole" ordinate da Biterbo e dal fratello Leone e che avevano un riferimento concreto nel passo: "Hospes fui et collegistis me" del vangelo di Matteo (Matt. 25,34) impiegato, come vedremo, di là a pochi anni, anche a Milano. Nel redigere il documento, inoltre, vennero toccati, puntigliosamente, molti aspetti dell'istituirsi di quelle due nuove organizzazioni, l'una esclusivamente ecclesiastica, l'altra, probabilmente, da gestire in una forma di cooperazione con i lai$\mathrm{ci}$, secondo le disposizioni dei canoni. Veniva tolta la possibilità, a qualsiasi altra persona, anche ai benefattori, di disimpegnare lo sforzo economico e spirituale concentrato nelle fondazioni; nessun vescovo, laico e priore avrebbe potuto aver voce nell'elezione del rettore. Un lungo ed elaborato anatema solenne avvalorò quindi quanto fino a quel momento era stato disposto nella transazione di Biterbo e dei "suoi".

Una delle singolarità dell'atto viterbese, che qui ancora non è stata presa in considerazione, riguarda la sottoscrizione del venerabilis presbiter Biterbo. Nel brevissimo passaggio tra la sottoscrizione del vescovo e quella dello "scriptorem Anastasius infelix sacerdos", probabilmente, della chiesa di San Silvestro, luogo dove venne rogato l'atto e per la quale Anastasio doveva nel caso ricoprire le funzioni di notaio ${ }^{17}$, per Biterbo, vennero utilizzate forme e formule presuntuosamente ammiccanti alle consuetudini della cancelleria papale come di quella im-

\footnotetext{
${ }^{16}$ Frezza, 2000, pp. 120-121.

${ }^{17}$ Liva, 1979, p. 60.
} 
periale. Osservando la charta riconosciamo la grandezza del modulo della capitale epigrafica, la predilizione per un elaborato modo di siglare il nome di Biterbo che ricorda la "rota"; la scelta, poi, presuntuosa di farsi definire "servus servorum Dei", impiego solitamente riservato ai vescovi e al pontefice romano, può essere in diretto rapporto con l'altrettanto singolare ed elitaria scelta di scolpire, a perenne memoria, un "estratto" monumentale dell'atto notarile.

\subsection{La "charta lapidaria"}

La carta lapidaria di S. Maria Nova ${ }^{18}$ risulta essere la più antica delle epigrafi del corpus viterbese; ancora oggi è posta nella sua sede originaria, collocata, come si diceva vicino all'ingresso della chiesa, all'inizio della navata di destra, venne sicuramente predisposta riprendendo i punti fondamentali della pergamena poi scolpiti su tre delle quattro facce del cippo marmoreo. Nel passaggio dalla pergamena all'iscrizione il documento venne elaborato in modo che il testo nella sua sostanza sarebbe risultato un "estratto" della charta originale. Si osserva, infatti, l'assenza di alcuni elementi protocollari del documento redatto nel 1080 come, per esempio, le sottoscrizioni dei testimoni mentre si intuisce il lavoro svolto per distribuire il testo della carta sulle tre facce del parallelepipedo di marmo. L'eccezione più forte rispetto al documento manoscritto fu l'introduzione nella prima parte dell'epigrafe dell'elemento narrativo e quindi la costruzione di un nuovo rapporto tra la scrittura epigrafica e la rispettiva charta. La prima parte dell'iscrizione, quella che caratterizza e differenzia questo testo dai molti altri incisi, è segnata dalla scelta di dare al testo epigrafico il valore di breve inserendo nel rigo $5^{\circ}$ del primo specchio dell'epigrafe, il predicato fecerunt anticipato da "hoc factum est imp(er)p(etuum) recordatione" ${ }^{19}$. Nonostante qualche difformità dobbiamo in ogni caso riconoscere, a chi predispose il testo inciso, la notevole capacità di organizzazione letterale dal momento che, a questa prima parte dell'epigrafe, caratterizzata da quella formula scrittoria del breve, quindi una "scrittura pratica", "di memoria" ${ }^{20}$, fu affidato l'onere impegnativo di elencare tutte le disposizioni a carattere generale imposte dai benefattori di quella Chiesa, quasi a voler perfezionare ulteriormente il documento manoscritto steso solo qualche tempo prima. Ricordiamo, in ogni caso, che il valore intrinseco del documento epigra-

${ }^{18} \mathrm{Cfr}$. Appendice documentaria, n. 2 Charta lapidaria cit.

${ }^{19}$ Bartoli Langeli, 2003, pp. 1-23, alla p. 20. Se il testo inciso nella prima faccia del cippo marmoreo segui "da manuale" I'andamento narrativo riconosciuto al prototipo del breve, così come Attilio Bartoli Langeli spiega essersi consolidato durante il secolo XI, riconosciamo comunque in questa prima parte dell'incisione un certo adattamento similare al documento manoscritto dal momento che in apertura compare la formula di datazione, peraltro risultata non congrua (a questo proposito cfr. Bottazzi, 2006a, p. 314), che normalmente, come Attilio Bartoli Langeli insegna, nel breve dovrebbe ricoprire lo spazio ultimo del documento.

${ }^{20}$ Ivi, p. 3. 
fico è proprio quello della memoria, qualità dunque molto simile all'essenza del "breve". In questa prima parte dell'iscrizione troviamo allora l'oggetto primo del negozio giuridico: si viene a conoscenza dell'istituzione della canonica; leggiamo della dedicazione della chiesa alla Vergine; viene ricordata la motivazione della donazione di Biterbo e Leone, a fronte della salvezza delle loro anime come per quella di tutti gli altri fedeli cristiani; inoltre non furono tralasciati i precetti ordinati alle istituzioni, canonicale e ospedaliera, decretate formalmente attraverso la carta del 1080 a vantaggio dei pellegrini e dei mendicanti; il tutto in uno specchio marmoreo molto ristretto ed entro il quale la scrittura capitale scelta per incidere la carta lapidaria risulta chiara e spaziata, dal ductus non sempre regolare, comunque "posato" e mosso solo da un controllato impiego di nessi. Nel complesso un'esecuzione ordinata in cui non si rilevano forti caratterizzazioni, se non l'uso importante del segno tachigrafico per et. Lo spazio limitato a disposizione non consenti di procedere oltre e nell'incidere la seconda faccia dell'epigrafe l'andamento della forma passò ad una fisionomia più usuale per un'epigrafe: quella della forma soggettiva. Nella sostanza la fisionomia del documento lapideo si avvicinò, a questo punto, di più a quella della charta, ovvero al documento originale manoscritto del 1080, dal quale l'iscrizione assunse tutti i restanti elementi già inseriti al presente - "volumus; rogamus" - seppur mantenendo un ultimo elemento distintivo del breve. Nell'inserire nell'epigrafe il nome del vescovo Giselberto, il committente o i committenti preferirono affidare all'alto prelato il ruolo di "ispiratore" ${ }^{21}$ delle due nuove istituzioni ecclesiastiche piuttosto che quello anche di garante, che invece ebbe nel documento manoscritto.

La terza e ultima faccia incisa dell'epigrafe lapidaria di S. Maria Nova, che per buona parte è stata detta "ordinata e leggibile", in quell'ultimo specchio lapideo divenne il luogo dell'effettiva memoria, in special modo là dove anche il ductus cambia. L'incisione divenne più irregolare e l'esito di mani diverse da quelle che precedentemente avevano inciso i primi due lati del parallelepipedo. Tre generazioni della famiglia di Biterbo sono infatti ricordate con sintetiche note obituarie, ma non si andò oltre la nipote di Biterbo, Pretia; rimase vuoto, infatti, lo spazio predisposto sul quarto lato del cippo marmoreo rosso dalle misure di $\mathrm{cm} 38 \mathrm{di}$ larghezza, $\mathrm{cm} 34$ di spessore per $\mathrm{cm} 76$ di altezza.

Una cosa potrebbe essere ancora aggiunta circa la datazione della charta lapidaria, che risulta non congrua rispetto a quella del documento originale dello scriptor Anastasio, dal momento che il dettato marmoreo venne scolpito a qualche anno di distanza, dopo il 1080, inserendo, nel secondo rigo dell'iscrizione, il riferimento all'imperatore Enrico IV assente nel testo manoscritto della charta.

A(nno) D(omini) MLXXX I(N)D(I)C(CTIONE) III T(EM)P(ORI)B(US) G(RE)G(ORII) P(A)

$\mathrm{P}(\mathrm{E})$ || Imp(erator) Henrico obsidente Roma(m)

\footnotetext{
21 "Itaq(ue) sagacissimus B(iterbus) sac(erdos) et Leo g(ermanus) initoq(ue) consilio una cu(m) Giselb(er)to e(pisco)po S(an)c(t)e T(uscaniensis) ecle(sie)".
} 
Un'inclusione, ovviamente, estranea rispetto al testo originario del 1080 spiegabile pensando all'atteggiamento di rottura sociale e politica generale vissuta da Viterbo, osservabile nelle formule della documentazione viterbese membranacea dello stesso periodo in cui, pensiamo, venne incisa anche la charta lapidaria per S. Maria Nova ${ }^{22}$.

\section{Carità e benevolenza laica; le "chartae" per l'Ospedale di S. Simpliciano di Milano}

A solo qualche anno di distanza dalla carta lapidaria per S. Maria Nova si colloca, seppur in altro contesto geografico italiano, quello molto fecondo milanese, quella prodotta per l'ospedale laico di S. Simpliciano. Nello studio dell'attività assistenziale italiana da sempre spicca il "caso lombardo"23 per il quale Giacomo C. Bascapé, nell'ambito delle sue mansioni svolte negli anni trenta del Novecento per l'archivio storico dell'Ospedale Maggiore di Milano, raccolse tutta una serie di testimonianze documentarie che palesarono la stretta relazione dei ricoveri milanesi, assieme a quelli della pianura lombarda, con le vie del pellegrinaggio e del grande movimento commerciale verso Roma, i paesi orientali e verso il Levan$t^{24}$. Anticipatamente rispetto alle altre città italiane, a Milano, già alla fine del $X$ secolo, sono attestati, infatti, importanti centri assistenziali per lo più organizzati inizialmente dai monasteri e più tardi, verso la fine dell'XI, affiancati a quelli, ma fondati e amministrati da laici per i poveri e per i pellegrini. L'importante "movimento" di carità e benevolenza laica milanese, che iniziò a mobilitarsi alla fine delle dure lotte per la riforma della Chiesa, aveva preso sempre più piede proprio grazie anche alla grande fase di espansione economica e sociale già accennata che, in via generale, ma più distintamente nella Lombardia, le città avevano iniziato a vivere intensamente dalla fine degli scontri nati dalla lotta tra papato e impero e con l'affermazione dei vari movimenti collettivi, tanto da spingere molti boni homines del laicato, pervasi da profonde inquietudini religiose e ormai politicamente ed economicamente autonomi, a stringersi attorno ai cenobi cittadini e agli hospitales che andavano aprendosi. Molte di quelle situazioni, a Milano, sono avvalorate da un numero discreto di chartae lapidariae a noi giunte per tradizione indiretta ${ }^{25} \mathrm{e}$ in taluni casi ancora presenti all'interno delle chiese. Come più volte sottolineato, sono tutti testi scolpiti che in molti casi riportano inciso "in toto" quanto in sede notarile era stato disposto nei testamenti e nelle chartae iudicati o, in alcuni casi, solo la parte dei legati disposti all'ente beneficato; fra tutti

\footnotetext{
22 Bottazzi, 2006/a, p. 314.

${ }^{23}$ Bressan, 1981, pp. 24-25.

${ }^{24}$ Bascapé, 1936, pp. 129-169, in particolare p. 129.

${ }^{25}$ La prima trascrizione del dettato lapideo prodotto per celebrare l'ospedale laico promosso da Lanfranco per i poveri accanto al ricovero di S. Simpliciano si deve a Serviliano Latuada, 1737 - 1738.
} 
gli importantissimi esempi di carte lapidarie finora rintracciate a Milano ${ }^{26}$, che rappresentano il substrato culturale importante di una evoluzione documentaria che per ciò che riguarda l'impiego epigrafico riprendeva dalla tradizione romana l'impiego delle iscrizioni contenenti atti pubblici e privati, apposti in luoghi di particolare passaggio e servizio pubblico ${ }^{27}$, emerge il caso eccezionale dei coniugi Lanfranco e Fraxia per l'ospedale da loro fondato, affiancato al monastero di S. Simpliciano, all'epoca uno dei grandi collettori dell'assistenza milanese ${ }^{28}$.

\subsection{La charta lapidaria di Lanfranco e Fraxia e le due chartae notarili}

II "caso" emblematico dell'ospedale di fondazione laica affiancato al monastero benedettino di S. Simpliciano, già analizzato in precedenza per un precedente contributo, viene qui ripreso sulla base di nuove sollecitazioni e riflessioni nate da una nuova testimonianza documentaria e guardando, con occhi diversi, allo stretto rapporto che si costruì con l'eccezionale presenza di una charta lapidar$i a^{29}$, della sua corrispondente charta notarile ${ }^{30}$, di fatto un testamentum rogato solo dopo che una prima carta notarile, uno iudicatum, molto più ampio ed elaborato, contenente patti successori, indicazioni e clausole era stato stilato, corroborato e considerato, fuori dalla sede notarile, poco adatto a ciò che i coniugi Lanfranco e Fraxia si erano apprestati a fare il 29 agosto del 1091.

L'eccezionalità del caso, che si vuole presentare di seguito al più semplice esempio viterbese, sta, dunque, nella straordinaria presenza di ben due carte notarili dovuta alla probabile ritrattazione avvenuta tra i convenuti, come si diceva, fuori dalla prima sede notarile; fatto che ha portato a una revisione del primo atto e alla redazione di una seconda carta, di fatto, il documento che sta a monte, poi, della carta lapidaria per l'ospedale di Lanfranco e Fraxia, rogata lo stesso giorno alla presenza di un notaio diverso dal primo; dinanzi ad un alto rappresentante dell'istituzione regia, diversa dunque dalla prima imperiale, che sottoscrisse, assieme a testimoni diversi dalla prima redazione, un testo molto più snello e di entità diversa che, nel suo tergo porta la precisazione "Carta domini Lanfranchi de la Pilla conditor hospitalis prope monasterium Sancti Simpliciani cuius tenor subnixium est in quodam lapide marmoreo <super portam> ipsius hospitalis"; frase scritta da una mano non molto più tarda di quella che rogò e stese quel secondo atto, che seppur differenziandosi, mantenne dei punti di contatto con la prima pergamena che si cercherà di delineare più estesamente.

\footnotetext{
${ }^{26}$ Bottazzi, 2012, pp. 319-329, 331-336.

${ }^{27}$ Buonopane, 2009, pp. 218-231.

${ }^{28}$ Bottazzi, 2012, pp. 321-329, 331-336.

${ }^{29}$ Silvagni, 1944, tav. VI, fig. 6; cfr. appendice documentaria n. 3.

${ }^{30}$ Archivio dell'Ospedale Maggiore di Milano, "Pergamene del secolo XI", n. 3; cfr. appendice documentaria n. 4. L'atto, in molte parti illeggibile, è stato edito, sia pure con le evidenti incertezze, alla fine degli anni sessanta del Novecento da Cesare Manaresi e da Caterina Santoro (cfr. Manaresi, Santoro, 1969, n. 765, pp. 392-394).
} 


\subsection{La prima carta di Lanfranco}

Su di una fine e chiara, seppur rovinata, pergamena di dimensioni medie, seguendo le leggere linee di scrittura tracciate posteriormente a secco, Aldo, "notarius sacri palatii", rogò, secondo la consuetudine notarile milanese del periodo, di seguito al suo signum tabellionis, le disposizioni di Lanfranco de la Pilla, che dichiarava di professare la legge salica. La formula molto "piana", ma fondamentale: "presens presentibus dixi" che avvia a una conclusione l'arenga, consenti al notaio di entrare, dopo i soliti rimandi alle motivazioni etico-morali e al passo evangelico di Matteo 25,34 impiegato anche a Viterbo, in medias res delle disposizioni di Lanfranco, probabilmente fino a quel momento espresse solo verbalmente e che l'atto avrebbe convalidato pur rimanendo in ogni caso ancora revocabili. Seguirono quindi la descrizione prediale dei beni che Lanfranco aveva disposto a favore dell'ospedale, per i quali spiccava la situazione "libellaria" di una loro parte, sicuramente molto salda, ma difficilmente quantificabile, che nella carta entrò nella dotazione dell'ospedale che si istituiva. Il notaio, quindi, ritornò sulle giustificazioni dell'intera donazione fortemente voluta da Lanfranco che dichiarò essere "pro remedium anime mee et animarum ipsius quondam Petri genitoris mei et Fraxie coniugis mee seu omnium fidelium defunctorum"; e su probabile indicazione sempre del disponente, senza troppe involuzioni, in modo circostanziale, venne affrontata la sistemazione successoria anche del resto dei beni di Lanfranco, che l'atto decretò dover rimanere in usufrutto vitalizio alla moglie Fraxia, ma per la quale vennero predisposte delle clausole pattizie ben definite. La condizione imposta a ciò che l'usufrutto fosse goduto da Fraxia era che la stessa "[in] castitate permanserit"; nel caso contrario, se la moglie si fosse risposata "ipse omnes res cum eorum frugibus et redditibus, quos annue Dominus dederit", sarebbero state "in potestate et dominio de ipso hospitali". Agli occhi dei futuri amministratori dell'ospedale, più avanti indicati, quel passaggio troppo vago sul futuro di una parte sicuramente importante, non ben quantificabile del patrimonio a quel punto molto incerto di Lanfranco, perché legato al futuro di Fraxia, iniziò a nostro parere a preoccupare. Le modalità riguardanti la gestione amministrativa e il patrocinio a difesa dell'ospedale e dei beni che Lanfranco donava venivano di seguito affidati ai boni homines che abitavano Porta Comacina, una struttura sociale "di quartiere" indicata dal disponente come, a quel punto, vitale per la vita dell'ospedale; d'altro canto molto aggirabile legalmente perché non ancora pienamente istituita. Sulla vita dell'ospedale sarebbero dunque pesate troppe incognite che avrebbero lasciato spazio alle possibili aspirazioni dell'importante e più forte monastero benedettino di S. Simpliciano che, di fatto, molto più tardi si sarebbero concretizzate ${ }^{31}$. Alle condizioni dettate seguì la consueta serie di anatemi declinati contro tutti i possibili soprusi di tutte le alte autorità laiche o ecclesiastiche di potere esterne all'ospedale in modo da offrire, come

${ }^{31}$ Sommerlechner, 2010, pp. 179-181. 
da consuetudine, maggiore sicurezza e tranquillità al donatore che in chiusura, sempre guardando alla consuetudine dichiarò di voler mantenere stabile l'azione giuridica del suo giudicato rafforzata dalla "stipulatione subnixa" e alla quale seguì la formula della tradizione salica che chiudeva l'atto stipulato "in suprascripta civitate Mediolani". Lanfranco pose il suo signum come principale attore dell'atto (fieri rogavit); vennero quindi quelli dei cinque testimoni: Arnaldi, qui dicitur de Piro e Arnaldi Sili, che dichiararono essere anch'essi di legge salica32; e quelli dei fratelli: Ambroxii, qui dicitur Pasquale, Petri e Amizonis. Pose, inoltre, il suo signum, Ambroxius anche detto Paganus iudex ac missus domini tercii Henrici imperatoris regi ${ }^{33}$; infine Aldus notarius sacri palatii, autore del giudicato steso impiegando una scrittura dal modulo rotondo e dal ductus regolare, caratterizzata dall'impiego di segni tachigrafici e da un uso non molto puntuale di quelli diacritici come da un moderato impiego di maiuscole, portava a compimento la completio con la usuale formula che si nota sulle chartae milanesi "Ego...scripsi, post traditam complevi et dedi".

\subsection{Le parallele carte di Lanfranco e Fraxia e la charta lapidaria}

Quelli appena elencati sono, nella sostanza, i punti distintivi del primo atto sottoscritto da Lanfranco de la Pila dinanzi ai cinque testimoni e ai due giudici messi imperiali; elementi, tutti, da confrontare alla luce del secondo documento rintracciato nello stesso fondo d'archivio dell'ospedale Maggiore di Milano. Come è stato già detto, nella stessa giornata, a distanza di poche ore dal primo testamento di Lanfranco, un secondo venne stilato di fronte al nuovo notaio Guglielmo, "iudex et missus domini secundi Conradi" che corroborò il documento. Alla seconda stesura intervennero ovviamente Lanfranco, che dichiarò - con una formula diversa dalla precedente - " levavi de terra calamum cum atramento, ut meum testamento ita scriberetur et porrexi", la formula tipica della legge salica; quindi Lantherius, detto de Solario; Arnoldus de Pillo, Arioldi Segeprandi di Guillelmus [...] pater et filii; Anselmus Ruscus; Guillizonus Portendrius; lohannes de Clocario, Amizus Pesapane, Arioldus Claus; Iohannes Baxabigia, Vasallus de [...], dieci testimoni presumibilmente identificabili tra i boni nomines di Porta Comacina; infine, il "testamento" - questa la precisa definizione impiegata per il secondo atto no-

32 In altra veste, nel 1092, Arnaldi, qui dicitur de Piro e Arnaldi Sili compariranno anche nel 1092, dinanzi allo stesso notaio Aldo con Fraxia, nell'ambito di una cessione di un livello ancora a favore dell'ospedale voluto da Lanfranco che nel documento viene detto "in via di costruzione" (cfr. Manaresi, Santoro, 1969, n. 765, pp. 392-394.

${ }^{33}$ Ambrogio detto anche Pagano, giudice e messo dell'imperatore Enrico $\langle\mathrm{IV}\rangle$ compare anche in altri due atti rogati a Milano ed editi nel Codice Diplomatico della Lombardia medievale tra le carte del fondo di Morimondo, Santa Maria I. II primo documento è una "Notitia ad futuram tenendam memoriam et securitatem" 1093 marzo 5, Milano; e in una cartula promissionis inserita nel Codex Sicardi: Cartula Promissionis, 1097 agosto 25, Milano; altri elementi biografici per Ambrogio reperibili in Lucioni, 2011, pp. 118-119. 
tarile - redatto e tradito venne consegnato da Ardico, "notarius sacri palatii", per essere conservato dal nuovo ente caritatevole.

Da un primo veloce raffronto delle due pergamene ciò che colpisce, rispetto al primo giudicato di Lanfranco, che si estende su trentacinque linee di scrittura, è la brevità della seconda carta, stesa su diciotto righi di una pergamena molto più piccola della prima e organizzata con altrettanta cura. È inoltre ben evidente il diretto legame di questa seconda, più succinta, "ultima" disposizione con l'epigrafe che verrà scolpita per essere apposta monumentalmente, pensiamo in un momento appena più tardo, a una delle pareti dell'ospedale di San Simpliciano, e il cui testo ricalcò il secondo documento, distanziandosi in almeno due punti dal primo parallelo ${ }^{34}$. Se nel redigere il nuovo testamento venne mantenuto lo schema del prototipo, si impiegò una formula invocativa, poi ripresa in epigrafe, che caratterizzò l'atto; più sintetiche furono anche le altre invocazioni, le formule e l'anatema impiegate nella prima stesura, come si osservano alcune sostanziali esclusioni riguardo alla vera sostanza del nuovo testamento disposto a diretto beneficio dell'ospedale laico di S. Simpliciano. Nel nuovo documento, inoltre, venne inserito un primo elemento del tutto estraneo al suo precedente notarile e che nell'epigrafe venne, poi, riprodotto pedissequamente: in prima persona Lanfranco e la moglie Fraxia "disponevano", che all'ospedale da loro fatto costruire dovessero spettare le stesse "octo iugera de terra vel si amplius fuerit de mea libellaria in Prato Centenario, in Nivuarda de vineis iugera duo et tabulas octo". In quella nuova sede Fraxia appariva accanto al marito nell'atto di disporre a favore dell'ospedale, investita del ruolo di donatore con la stessa capacità giuridica e dispositiva del marito; e come tale sarebbe apparsa anche nella più tarda epigrafe. Rispettando poi le prime disposizioni notarili, nel nuovo testamento venne inserita ancora una sostanziale variante poi riportata anche nella forma epigrafica: venne completamente rimosso il ricordo che Lanfranco aveva dedicato al padre Pietro. Nel secondo atto vennero, quindi, chieste preghiere per la salvezza delle sole anime di Lanfranco e di Fraxia, inoltre non venne fatta menzione alcuna circa la clausola imposta in prima battuta alla moglie, se vedova, né venne fatta menzione del fatto che di fronte a un nuovo matrimonio di Fraxia la totalità dei beni di Lanfranco sarebbero passati immediatamente e completamente all'ospedale $e^{35}$. Infine, se Lanfranco nel primo giudicato aveva disposto che la gestione e la difesa della sua istituzione ospedaliera appena nata doveva rimanere nelle mani dei boni homines abitanti entro la vicinia di Porta Comacina, nel suo secondo testamento, il lungo e puntiglioso ordinamento riguardante l'elezione dei rettori dell'ospedale venne sinteticamente compreso in due sole righe, che sottolinearono solo la piena giurisdizione e difesa dell'ospedale da parte dei boni homines

\footnotetext{
${ }^{34}$ Si propone un confronto tra le pergamene e il testo lapideo; cfr. Appendice documentaria, nn. 3, 4 e 5 .

${ }^{35} \mathrm{cfr}$. Archivio dell'Ospedale Maggiore di Milano, Pergamene del sec. XI, n. 4, cfr. appendice documentaria n.5.
} 
Portae Comacinae ${ }^{36}$, che in questo caso furono i diretti protagonisti di quella nuova forma di carità cristiana.

Tutte le disposizioni ordinate vennero infine difese, come nel primo giudicato, impiegando una formula di anatema più concisa e veloce e riducendo la prima motivazione salvifica di Lanfranco che ora diveniva - "pro remedio animarum nostrarum et omnium qui huic hospitali suas contulerint res et id defensaverint seu omnium fidelium defunctorum" -. II padre di Lanfranco, Pietro, rimase infatti completamente escluso, anche nell'epigrafe, dalle preghiere da dispensare sulla base del secondo testamento. Un'ulteriore distanza si nota ancora nella formula della completio notarile che risulta mancante della formula: "cum stipulatione subnixa" inserita invece nel giudicato. Come già detto, nella completio Lanfranco comparve come il diretto fautore del negozio espresso grazie alla formula salica. Quindi seguirono le sottoscrizioni dei testimoni, come già detto, convenuti in numero maggiore rispetto al momento precedente e da immaginare come i boni homines di Porta Comacina. Ovviamente nella redazione epigrafica la sottoscrizione venne sostituita da una più conforme nota obituaria a memoria dell'estremo, ultimo, atto di Lanfranco: "Obiit autem ipse Lanfrancus vigesimo die mensis septembris, anno dominicae incarnationis millesimo nonageximo primo, indictione decima quinta", di fatto un elemento nuovo e rilevante che andò a perfezionare il testamentum rogato in seconda sede notarile. Lanfranco mancò a Fraxia il 21 settembre del 1091, ventitrè giorni dopo che i suoi atti, corroborati dai notai Aldo e Ardico, istituirono e dotarono l'ospedale affiancato al monastero di S. Simpliciano

Ovviamente, non possiamo dire con certezza che cosa portò alla redazione del secondo atto, che sembra non avere escluso il precedente giudicato, inspiegabilmente rimasto infatti "attivo" tra le carte dell'ospedale; né possiamo aggiungere il nome di chi possa aver scelto di riportare, poi, il tutto in epigrafe. È immaginabile che la decisione di produrre una "carta lapidaria" possa essere stata presa dagli amministratori dell'ospedale ad imitazione dei più antichi esempi apposti entro la chiesa del monastero di S. Simpliciano ed esposti a memoria di Guillitionus de Summa (fine del secolo X o primi anni dell'XI) ${ }^{37}$ e di Azzo e Reiza (1039), altri precedenti e importanti benefattori molto più legati di Lanfranco all'istituzione monastica, che donarono importanti parti delle loro sostanze ben evidenziate in epigrafi di grandi dimensioni, probabilmente fatte esporre dal monastero quasi a rafforzamento, data la grande forza comunicativa del monumento marmoreo, di quelli che dovevano essere i pieni diritti del monastero sulle proprietà donate. Sulla base allora di quest'ultima riflessione è bene ritornare, allora, ancora un attimo sulla carta lapidaria dell'ospedale di Lanfranco a fronte di un terzo documento. Se, infatti, nella descrizione prediale del giudicato e del testamento di Lanfranco venivano donati all'ospedale "octo iugera de terra vel si amplius fuerit de mea libellaria in Prato Centenario, in Nivuarda de vineis iugera duo et tabulas

\footnotetext{
${ }^{36}$ Ibidem.

${ }^{37}$ Lucioni, 2006, pp. 35-77.
} 
octo", nell'epigrafe scolpita dopo la morte di Lanfranco i beni destinati all'ospedale apparivano più consistenti. Le righe dell'epigrafe documentano una devoluzione aggiuntiva: "in Nivuarda (...) campis perticas tres; in Cinixello iugera septem perticas tres; in Balsemo perticas decem et octo". II reddito maggiore dovette pervenire, dunque, da soluzioni, in parte ancora sconosciute, probabilmente perdute, dal momento che abbiamo contezza di solo una piccola parte di esse grazie a un terzo atto rogato dalla vedova di Lanfranco il 1 maggio $1092^{38}$, nuovamente dinanzi al notaio Aldo, che rogò il primo giudicato di Lanfranco. Questo terzo documento sembra aggiungere alla storia di Lanfranco e Fraxia e del loro ospedale un piccolo indicativo tassello utile alla ricostruzione della proprietà devoluta dai coniugi. Fraxia il 1 maggio del 1092, a meno di un anno dalla morte del marito, ritornò ad essere documentariamente "partem et utilitatem hospitalis" prendendo a livello da Arnaldo del fu Adamo de Piro e dai suoi nipoti Paulenzone e Anselmo, già presenti come testimoni nel primo atto, "usque in perpetuum" un "pezzo de terra iuris monasterii, Sancti Simpliciani" situata fuori Milano. La terra era in parte rimasta "in benefitium" dello stesso monastero e in parte data a livello ad Arnaldo e ai nipoti, che l'avevano ceduta a Fraxia. Anche questo terzo atto del notaio "Aldus sacrii palatii" rimase piuttosto vago; non abbiamo indicazione del luogo preciso del terreno che Fraxia avrebbe preso a livello per l'ospedale, né l'entità del suo valore; sappiamo solo che si trattava di un terreno di 29 tavole (circa 790,8587 metri quadri, ovvero 0,079 ettari) e che il censo ricognitivo da pagare entro il 15 agosto era di una candela. Siamo, dunque, molto distanti dal ricostruire documentariamente il patrimonio che in epigrafe, facendo le debite proporzioni, è ricordato essere nelle mani dell'ospedale in misura superiore a duecento quattro pertiche, ovvero a tredici ettari e mezzo circa.

\section{Le carte lapidarie di Collescipoli}

Inserito in quelle che, nell'XI secolo, vennero definite le "Terre Arnolfe", che Enrico Il cedette al Papa in cambio di terre papali in Carinzia, il centro di Collescipoli, entro il primo ventennio di quel secolo era divenuto, dunque, parte del territorio della Chiesa, per la quale gli Arnolfingi continuarono ad essere feudatari e devoti all'abbazia di Farfa.

Nel panorama monumentale documentario italiano la piccola chiesa di S. Stefano esterna all'abitato di Collescipoli si inserisce come il luogo in cui vennero apposte due delle più significative chartae lapidarae fino ad oggi raccolte, un genere che abbiamo imparato a riconoscere, ma che a Collescipoli, presentano qualche ulteriore, importante caratterizzazione utile a definire sempre più efficacemente il rapporto tra la documentazione manoscritta medievale, le chartae e quella monumentale scolpita: le epigrafi. A Collescipoli, ancora una volta, i documenti risposero all'esigenza dei committenti di promuovere, in modo ampio

${ }^{38}$ Manaresi, Santoro, 1969, pp. 405-406; Sommerlechner, 2010, pp. 176-179. 
e pubblico, quanto venne disposto pro redemptione animae da facoltosi offerenti a favore di un'istituzione religiosa. Se, però, solitamente sappiamo che le carte lapidarie dovevano contenere, in via generale, solo una parte dei legati di un giudicato, ovviamente quelli a favore dell'ente beneficiato, che avrebbe poi provveduto ad esporre un'epigrafe ad perpetuam memoriam del lascito ricevuto, più insolitamente invece a Collescipoli ciò che venne riprodotto è una charta donationis, tràdita e scolpita con unico intento pio, completa di un secondo atto susseguente: un breve dal valore obbligazionale, ricco di continui rimandi alla tradizione giuridica giustinianea e che andò a perfezionare, rinforzandolo, l'intero negozio giuridico inter vivos stretto tra numerose e diverse persone il 18 febbraio del $1094^{39}$.

Quest'ultimo esempio di carte lapidarie che qui viene proposto è il risultato di uno studio pubblicato nel 2012 sotto la guida di Attilio Bartoli Langeli e che qui riprendo dal momento che meglio di ogni altro esempio definisce lo stretto rapporto tra la documentazione notarile e le carte lapidarie, in questo caso ricche di continui rimandi agli originali notarili ${ }^{40}$.

L'intimo impiego epigrafico/documentario che diede vita alle due iscrizioni di Collescipoli, che vantano una bibliografia ormai cospicua ${ }^{41}$, è per questi due testi scolpiti un caso che può dirsi unico tra le carte lapidarie, ancora più interessante se percepiamo le due iscrizioni apposte alla chiesa di S. Stefano di Collescipoli come le copie di due ordinari documenti notarili del loro tempo, consapevolmente e volutamente intesi, prodotti e poi scolpiti per rendere la massima pubblicità possibile a una fondazione disegnata, già alla fine del secolo XI, secondo i canoni e la sacra lex ${ }^{42}$.

Il primo dei due atti incisi si presenta, infatti, come una charta, più specificatamente definita nel testo lapideo contractus, documento tradizionalmente idoneo ad attestare i trasferimenti di beni immobili a titolo definitivo sia nei passaggi inter vivos sia in quelli mortis causa; e a seguire, il secondo venne configurato, com'è già stato detto, come un breve, in questo caso un breve recordationis: diplomatisticamente un documento di più agile composizione e d'impiego eterogeneo, altrimenti assimilabile alle notitiae e ai memoratoria ${ }^{43}$; carattere che

\footnotetext{
${ }^{39}$ Cfr. Appendice documentaria n. 5 (Fig. 5). La datazione cronica scolpita sulle epigrafi di Collescipoli è: “Millesimo nonagesim(o) || ter(tio), Enrico quonda(m) Enrici impe || ratoris filio reg(nante), XII kal(endas) mar(tii) | | indic(tione) II" che rispondendo al computo fiorentino dell'indizione corrisponde al 18 febbraio del 1094.

${ }^{40}$ Bottazzi, 2012, pp. 501-522.

${ }^{41}$ Angelelli, 1995, pp. 91-99; Ead., 1997, pp. 139-159; Guerrini, 2010 pp. 98-118. Milj, 1800, pp. 83-85, 151-153.

${ }^{42}$ I riferimenti ai canoni e alla sacra lex si leggono nel r. 19, r. 29 della prima epigrafe e r. 43 della seconda epigrafe apposta alla destra sopra il portale della chiesa di Santo Stefano. ${ }^{43}$ Per un inquadramento generale sul "breve" cfr. Leicht, 1933; Barbieri, 1990; Nicolaj, 1996, pp. 153-198; Bartoli Langeli, 2003, pp. 1-23, anche in: http://www.isime.it/redazione/bull105bartolilangeli.pdf; Ghignoli, 2004, pp. 659-660; Nicolaj, 2007, pp. 180-215;
} 
solitamente ritroviamo nella scrittura epigrafica, specialmente se monumentale come quella esposta a S. Stefano. Fatto che a nostro giudizio attesta anche la strettissima e conseguente relazione percepita dagli autori e dai committenti di quelle due epigrafi di Collescipoli tra il "documento" e una consona prassi giuridica e notarile, oltre al rapporto che in quel momento del medioevo, per loro, doveva unire scrittura su pergamena ed epigrafia.

\section{1. "Contractus» e «breve recordationis» lapidei}

L'altezza e la dimensione del modulo capitale impiegato $(\mathrm{cm} \mathrm{1.5)}$ nell'incidere quelle iscrizioni non permettono un'agile lettura da terra dei 159 righi piuttosto sottili ma pronunciati di cui si compongono le iscrizioni apposte alla facciata della chiesa di S. Stefano. Nell'insieme ciò che si nota è un'ordinatio epigrafica piuttosto curata e strategicamente organizzata, rispettivamente su cinque colonne la prima iscrizione e su quattro la seconda. A separare centralmente i due testi epigrafici è una formella, anch'essa inscritta, in cui è stata scolpita a rilievo l'immagine di Cristo in croce circondato dagli angeli, da Maria e dai santi ${ }^{44}$. Riguardo all'ordinatio, ciò che è bene notare, è lo sforzo fatto da chi scolpì di riprodurre "fotograficamente" alcuni tratti del documento manoscritto. Ad imitazione, infatti, della documentazione manoscritta, le due ampie iscrizioni riportano il signum crucis e il nomen sacrum nella forma Xpi; si nota, poi, una particolare cura nel riprodurre le sottoscrizioni e i signa dei testimoni, il signum tabellionis e la completio del notaio, che nella prima epigrafe venne anticipata da un'abbozzata croce seguita dalla $€$ di ego, probabilmente nel rispetto dell'impiego manoscritto relativo alle litterae notabiliores, mentre nell'ultima lastra della seconda iscrizione il signum riprodotto del notaio Benincasa appare come un ricercato incrocio di foglie, probabilmente molto vicino a ciò che lo scalpellino deve aver ricopiato dalla pergamena originale ${ }^{45}$.

Ansani, 2006-2007, anche in http://scrineum.unipv.it/rivista/4-2007/ansani-brevia.pdf , 2007 Univ. di Pavia; Marrocchi, 2008, pp. 9-42; Zagni, 2003, pp. 1073-1091. Ansani, 2011, pp. 15-53.

${ }^{44}$ La piastra di marmo scolpita, centrale rispetto a tutto l'apparato monumentale e che rappresenta il Cristo in croce, la beata Maria e san Giovanni a sinistra, Santo Stefano e San Giovenale a destra, accoglie nella fascia inferiore l'iscrizione dedicatoria:

+ Ad honore $<m>$ Domini\{ni\}

le(s)u Xpi beate Marie virginis et beati

Stephani protomartiris adq(ue) lubenalis.

cfr. Bertelli, 1985 pp. 150-152.

${ }^{45}$ Cfr. Petrella, 1911, pp. 337-365, grazie al quale Toubert, 1973, segnatamente nelle pp. 113-134 e nella nota 2 di p. 127, si espresse sul tardo sviluppo dei signa in uso tra i notai romani come tra quelli del territorio laziale, segnalando invece il più consuetudinario impiego della formula della completio notarile introdotta da Ego; contesto istituzionale e 


\subsection{II "contractus", ovvero la "charta donationis"}

Anche a Collescipoli l'affissione delle epigrafi servì ad attestare dalla fine del secolo XI, come lo avranno fatto per lungo tempo anche gli atti originali perduti, la posizione giuridica di fronte alle diverse istituzioni locali delle persone che abitavano verosimilmente con una funzione eminente quel luogo e il suo territorio al tempo incluso nell'antica diocesi di $\mathrm{Narni}^{46}$.

Con il così detto contractus, la vera e propria charta donationis, il primo dei due documenti rogati dal notaio e avvocato Benincasa e poi incisi, Pietro e Bernardo, figli del fu Falcone, Litaldo e Gualfredo, figli del fu Rapizone, Guido e Tebaldo del fu Crescenzo, ai quali si unì Pepone figlio del fu Farulfo, dichiararono di voler affidare al prete Lupo, presumibilmente legato a loro da un rapporto di parentela ${ }^{47}$, la piccola chiesa monoabsidata dedicata alla Vergine e al martire Stefano, edificata infra pertinentiam castri Colliscipuri con omnibus suis dotalibus, dotazioni non meglio considerate nel testo epigrafico probabilmente perché oggetto di un precedente manoscritto non riprodotto, come il piccolo rimando inciso a de omnibus rebus que superius diximus della prima epigrafe sembra accennare in sostituzione di una descrizione prediale circa i beni predisposti in dotazione all'ente ecclesiastico ${ }^{48}$. Con il contractus vennero prescritti, ma solo unilateralmente, alcuni punti fondamentali della convenzione stretta tra gli interessati: il sacerdote Lupo e i suoi successori avrebbero dovuto dimorare presso la chiesa in presumibili locali adiacenti, verosimilmente adibiti a canonica. Con il contractus gli offerenti trasmisero al prete Lupo e ai suoi successori la potestà, il possesso, la reggenza e i benefici legati alla nuova istituzione religiosa nata per la redenzione delle loro anime come di quelle dei loro parenti. Per mezzo del contractus i donatori assicurarono una sorta di libertas ecclesiastica alla piccola chiesa per effetto dell'allora recente riforma religiosa, dal momento che in perpetuum su quella chiesa non sarebbe gravato il loro patronato laico mentre ad essa non doveva nemmeno mancare la protezione che i benefattori garantirono contro qualsiasi ipotetica intrusione, anche da parte dei propri discendenti. Nel contractus venne, inoltre, predisposta una sanzione a carico di chi donava equivalente a cento soldi di monete pavesi nel caso di un'inadempienza, elemento che ritroviamo anche in un altro precedente atto rogato dello stesso notaio Benincasa a favore dell'ab-

giuridico in cui si trovò ad operare a Collescipoli il notaio Benincasa, "Dei nutu notarius" ovvero "notaio per il volere di Dio". Riguardo ai signa notarili è sempre utile Paoli, 1942, pp. 318-320. Sui signa Bartoli Langeli, 2006, pp. 91-99.

${ }^{46}$ Cfr. Bertelli, 1985, pp. 55-62.

${ }^{47} \mathrm{Nel}$ primo testo epigrafico sono stati ben definiti i nuclei parentali, compreso quello di Lupo, il sacerdote a cui gli offerenti affidarono la chiesa; quest'ultimo patronimico venne notificato, però, solo nella parte finale del documento.

${ }^{48}$ Al rigo 23 della prima lastra, le parole incise: (...) de omnibus rebus que superius diximus (...), sembrano accennare a un primo, antecedente documento in cui vennero elencati $\mathrm{i}$ beni dati in dotazione alla chiesa di Santo Stefano. 
bazia di Farfa che rimanda allo stesso in uso nel ducato di Spoleto, tra la fine del secolo XI e il secolo $\mathrm{XII}^{49}$. Quindi, il documento marmoreo apertosi con il signum crucis, al pari dei documenti manoscritti, prosegue già in modo non comune per la zona geografica d'appartenenza con l'invocazione alla Trinità di tradizione bizantina: In nomine Patris et Filii et Spiritus Sancti, che sappiamo essere stata più specificatamente impiegata, ancora in quel periodo, dai tabelliones del Ravenna$t^{50}$. Seguì la sola datazione cronica caratterizzata da un rimando alla reggenza di Enrico IV, venendo esclusa, invece, quella topica, anche nella fase finale - l'escatocollo - dell'epigrafe. Conformemente a molte altre scritture epigrafiche del suo tempo, comprese quelle appene viste per Viterbo e per Milano, l'iscrizione venne chiusa con il peso di un anatema solenne seguito solo dall'abituale dichiarazione dei benefattori di aver proceduto spontaneamente alla stesura di quel contractus nell'aspettativa che le loro decisioni rimanessero ferme e immutate nel tempo; e invocando quindi una firmitas piena di "vigore ed efficacia"51 il contractus di Pietro e Bernardo, Litaldo e Gualfredo, Guido e Tebaldo, e Pepone, persone individuate come appartenenti alla famiglia di discendenti di un conte Arnolfo, fedele a Ottone III, e ravvisabili nel ramo dei conti di Sangemini, dei quali un Rapizone figlio di Arnolfo fu il primo ${ }^{52}$, venne sottoscritto da Litulfo del fu Chincone, da Bernardo del fu Leone, Pietro del fu Litulfo, da Adenolfo di Perone e da Pietro Ciozo, cinque testimoni comunemente previsti dal diritto giustinianeo non identificabili nella larga documentazione coeva. Vennero, invece, pienamente esclusi dalla sottoscrizione gli attori del documento, ovvero gli autori della donazione. Ad ogni buon conto la partecipazione e la testimonianza sottoscritta dei cinque testi, che a rigore dovevano essere stati presenti al compimento dell'atto, corredarono "della pubblicità e dell'autenticità" necessarie il contractus rendendolo valido e pronto per la ratifica del "notaio ed avvocato" Benincasa che post roboratione omnium testium, formula nuovamente attinta dalla tradizione romanistica, complevit et absolvit ${ }^{53}$.

\footnotetext{
${ }^{49}$ Per un ragguaglio importante sulla circolazione monetaria nell'Italia settentrionale e centrale alla fine del secolo XI cfr. De Luca, 1979, pp. 183-209. II primo documento, in assoluto, in cui viene nominato come rogatario il notaio Benincasa è nel regesto farfense. Anche in quella precedente occasione le penalità fissate nel documento rogato da Benincasa furono conteggiate in denari pavesi (cfr. Giorgi, Balzani, 1879-1914, vol. V, doc. 1128, pp. 191-192. La moneta pavese si prestava, infatti, a essere ancora a quel tempo "la più diffusa e prestigiosa" (cfr. A. De Luca, 1979, p. 194), garantiva sui mercati buoni accordi commerciali, che se stilati in modo calibrato promettevano di evitare, come venne inciso anche in epigrafe, qualsiasi ricorso al placito da ambo le parti (cfr. Padoa Schioppa, 1989, pp. 459-549).

${ }^{50}$ Santoni, 2009, pp. 73-83, alla p. 80.

${ }^{51}$ Nicolaj, 1996, pp. 153-198.

${ }^{52}$ Milj, 1800, pp. 67-84, in modo speciale alle pp. 83-84 in appendice Milj trascrisse l'intero testo delle due epigrafi (cfr. Milj, 1800, doc. II, pp. 151-153).

${ }^{53}$ cfr. Bartoli Langeli, 2003, pp. 45, 55-57; Santoni, 2009, pp. 80-81.
} 
Come già osservato, a questo primo testo inciso venne dato l'abitudinario carattere dispositivo e piuttosto formalizzato delle chartae altomedievali che trasferivano la proprietà delle $\cos ^{54}$, seppure l'unilateralità delle clausole sanzionatorie inserita nel documento epigrafico, che definì le obbligazioni a carico dei soli donatori, risulti essere per l'epoca il riflesso di una prassi singolare. La documentazione coeva a cui si fa normalmente riferimento abitualmente dispone in uno stesso atto vincoli e obbligazioni sia per il donante sia per il donatario; appare dunque molto diverso il procedimento scelto dal notaio Benincasa e che necessariamente avrebbe richiesto, non esplicitamente, e secondo il diritto romano anteriore a Giustiniano, un intervento diretto e isolato del solo donatore in un secondo e successivo documento ${ }^{55}$.

\subsection{La stipulazione, ovvero il "breve"}

Così, in modo poco conforme alle consuetudini notarili tracciate dalla tradizione del territorio non scevro della cultura latina e della pratica farfense, a sua volta influenzata dal diritto germanico, e forse più vicino alla prassi che vediamo impiegata nel secolo XI da alcuni notai del territorio lombardo ${ }^{56}$, per la chiesa di Collescipoli divenne più importante aggiungere, fuori dalla charta/contractus, ma di seguito ad essa, uno scritto dalla sostanza altrettanto dispositiva e unilaterale, svolto questa volta dal punto di vista del donatario e il cui tenore volle essere,

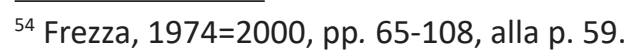

${ }^{55}$ Sui contratti che nel diritto romano generavano obbligazioni sono di grande aiuto Bertolini, 1905, fasc. 1, pp.6-143; e Bonfante, 1932, p. 469.

${ }^{56}$ A questo riguardo cfr. Manaresi, 1937, pp. 77-85, segnatamente alle pp. 77-78. Sull'impiego lombardo del breve in aggiunta alla "carta" cfr. la documentazione edita in rete da Ansani entro il Codice diplomatico medievale lombardo. Dall'archivio di S. Maria al Monte Velate edito da P. Merati, cfr. http://cdlm.unipv.it/edizioni/mi/velate-smaria1/ carte/smmonte1017-08-00a, 19, Breve<conventionis> <ante 1017 agosto>; di seguito http://cdlm.unipv.it/edizioni/mi/velate-smaria1/carte/smmonte1017-08-00b , 20, Carta promissionis, 1017 agosto, <in domo Brela>. http://cdlm.unipv.it/edizioni/mi/velate-smaria1/carte/smmonte1081-02-00a, 50, Carta venditionis, 1081, febbraio, Bobbiate; http://cdlm.unipv.it/edizioni/mi/velate-smaria1/carte/smmonte1081-02-00b, 51, Breve recordationis, 1081, febbraio, Bobbiate. Dall'archivio di S. Maria di Morimondo edito da M. Ansani, cfr. http://cdlm.unipv.it/edizioni/mi/morimondo-smaria1/carte/morimondo1093-03-05a, 20, Carta venditionis, 1093 marzo 5, Milano; seguirono: http://cdlm. unipv.it/edizioni/mi/morimondo-smaria1/carte/morimondo1093-03-05b, 21, Carta promissionis, 1093 marzo 5, Milano; http://cdlm.unipv.it/edizioni/mi/morimondo-smaria1/ carte/morimondo1093-03-05c, 22, Notitia ad futuram tenendam memoriam et securitatem, 1093 marzo 5, Milano. Un secondo esempio ancora parte dell'archivio di Morimondo, rogato a Pavia cfr. http://cdlm.unipv.it/edizioni/mi/morimondo-smaria1/carte/ morim1098-07-08a, 29 Libellus, 1098 luglio 8, Pavia al quale seguì http://cdlm.unipv.it/ edizioni/mi/morimondo-smaria1/carte/morim1098-07-08b, 30, Breve investiture et refutationis, 1098 luglio 8, Pavia. 
fin da principio, quello dispositivo e coercitivo della stipulatio, uno tra i contratti reali del mondo giuridico romano, generalmente utilizzato per costituire rapporti obbligatori specifici ${ }^{57}$; di fatto uno sfondo utile a rinforzare contratti consensuali ed entro al quale, nel caso di Collescipoli, vennero inserite tutte quelle pattuizioni speciali che non sarebbero potute rientrare nei soliti schemi documentari della charta/contractus e che trovarono, pertanto, miglior collocazione in un breve. Venne stilato pertanto un breve recordationis, dalla sostanza tuttavia molto dissimile da quella che siamo abituati a ravvisare comunemente fra la documentazione dell'epoca, sempre che si voglia prendere come riferimento quella tanto celebrata tipologia documentaria d'ambito privato: un testo di più semplice e malleabile attuazione, dalla funzione memoratoria, uno scritto solitamente destinato ad ospitare investiture, refute e obbligazioni, altrimenti capace di spazi narrativi ed ugualmente utile ad accomodare qualsiasi soluzione documentaria, anche sperimentale. Quel nuovo scritto, in modo molto simile a quanto visto per l'epigrafe di S. Maria Nova di Viterbo, già nella sua parte iniziale si risolse in modo dispositivo senza assumere il valore probatorio che generalmente siamo abituati a scorgere nel breve. Con parole che inizialmente rimandano, infatti, "al valore di quel documento attestante una cosa avvenuta" - "Facio breve recordationis ego Lupo presbiter tibi Peroni quondam filio Falconis (...)" ${ }^{\prime 58}$ - il notaio nel preparare quel suo secondo atto lo aprì assegnando al testo una forma ulteriormente essenziale e veloce rispetto alla consuetudinaria e formale charta. L'invocazione - In nomine Domini -, la datazione cronica e il riferimento all'impero di Enrico IV pur richiamando il precedente contractus vennero concepiti in modo molto simile ancora all'iscrizione di S. Maria Nova di Viterbo, in funzione di un documento molto più conciso, formulato secondo quel "duttile" modello documentario ${ }^{59}$; venne però nuovamente escluso qualsiasi riferimento topico, elemento che generalmente si ritiene come immancabile e qualificante in un breve, specie se di produzione lombarda, come non fu il notaio a porsi quale figura narrante, come tradizionalmente vediamo succedere anche a Farfa, bensì fu il sacerdote Lupo, il diretto attore dell'atto ${ }^{60}$. Nonostante ciò, il notaio che stilò il documento si affrettò, nell'immediato, a definire quel nuovo documento una "cartula"; richiamando più volte poi l'attenzione, nel corso del testo, sul valore intrinseco di quell'atto da ritenersi di fatto una "stipulatio". Solo nella parte finale del testo vediamo definire il documento "contractus". L'animus caratterizzante che si percepisce leggendo l'epigrafe fu in ogni caso quello stipulandi.

\footnotetext{
${ }^{57}$ Bonfante, 1932, pp. 447-452.

${ }^{58}$ Così Bartoli Langeli, 2006, p. 50; nella seconda epigrafe di Collescipoli al r. 20.

${ }^{59}$ Bartoli Langeli, 2003, pp. 1-23, alla p. 21.

${ }^{60}$ Sulla questione di chi fosse tenuto a redigere un "breve", quale documento costitutivo che riteniamo rapportabile al testo della seconda epigrafe di Collescipoli sono importanti le osservazioni di Attilio Bartoli Langeli (IVI, p. 19).
} 
Senza ripercorrere il dotto utilizzo romano della stipulatio ${ }^{61}$, che abbiamo visto impiegata anche per il giudicato di Lanfranco per l'ospedale di S. Simpliciano di Milano, non possiamo che orientarci verso quello che fu l'impiego medievale di quel genere di contratto ricordando che la formula tradizionalmente impiegata nella documentazione coeva all'epigrafe veniva inserita nonostante fosse noto ai notai il limitato peso obbligazionale di tale integrazione ${ }^{62}$. La prassi che vediamo impiegata in quel territorio influenzato da Farfa poteva prevedere l'inserimento della stipulatio, com'era già nel VI secolo nelle ultime righe del testo dei papiri ravennati, poco prima della consuetudinaria rogatio ${ }^{63}$. Nelle donazioni e nelle enfiteusi farfensi i notai preferirono comunque, più frequentemente richiamare la stabilità del contratto inserendo le formule: (...) unde pro stabilitate vestra hanc cartam scripsi; (...) et charta ista donationis vel concessionis semper habeat stabilitatem; e ad ogni buon conto si ha l'impressione che la formula della stipulatio subnixa, nel territorio influenzato da Farfa, venisse predisposta in atti di donazione cospicui per i quali si doveva prestare un'attenzione maggiore; oltre a ciò, quasi regolarmente vediamo aggiungere la formula relativa alla stipulatio subnixa in quelle chartae in cui il donante era un sacerdote ${ }^{64}$.

Data I'appartenenza di Lupo all'ambiente ecclesiastico, questo secondo documento inciso e apposto sullo stipite della porta della piccola chiesa di Collescipoli di seguito alla sua precedente charta non sembra essere, allora, un'eccezione, se non per il fatto di essere stato intimamente legato, come nell'antico impiego romano, al suo unico "attore" oltre ad essere stato comodamente vestito, in modo consapevole, dell'essenza di un breve rafforzato però da una stipulatio d'antico stile che avrebbe migliorato, nel caso, e in sede di giustizia, la posizione di chi donava; solo così il breve del notaio Benincasa avrebbe assunto la stessa forza costrittiva della charta ${ }^{65}$.

\footnotetext{
${ }^{61}$ Sull'impiego della stipulatio nel diritto romano preferisco rimandare alla larga letteratura segnalata da Giovanna Nicolaj, 1996, nota 20; Bertolini, 1905, e di Bonfante,1932, pp. 447-452. Per l'edizione dei papiri ravennati: Tjäder, 1954-1955. Sono diversi gli esempi di stipulatio impiegati anche nella documentazione ravennate del secolo VIII edita da Marco Fantuzzi; qui rimandiamo ad una delle tante testimonianze edite e in questo caso un exemplum ex autentico de Cartula Donationis: Fantuzzi, 1802-1804, II, a. 767, mart.3, pp. 1-4. Come nella carta ravennate del 767 la stipulatio venne inserita in modo formalizzato e a chiusura dell'escatocollo anche nei documenti dei secoli X, XI e XII. Tale impiego, recepito in modo speciale nel territorio romanico legato allo ius giustinianeo, risulta essere molto usato nelle carte farfensi, coeve alle epigrafi di Collescipoli, però nella sola formula standardizzata della stipulatio subnixa che gli storici del diritto reputano essere priva, a quell'epoca, dell'originaria forza obbligazionaria. Sull'impiego medievale della stipulatio cfr. Leicht, 1933, pp. 210-225.

${ }^{62}$ Cfr. Bertolini, 1905, nota 2, p. 77.

${ }^{63}$ Giorgi, Balzani, 1879-1914, vol. V, doc. 713, a. 1030, pp. 84-85; doc. 749, pp. 121-125.

${ }^{64}$ Bottazzi, 2012b, p. 516, n. 32.

${ }^{65}$ Possiamo aggiungere che la stipulazione inserita allora si può anche dire accessoria o
} 
A Pepone del fu Falcone e a Berardo suo fratello come a tutti gli altri nominati solo qualche momento prima nell'atto di donazione, ovvero a Litaldo, a Gualfredo, a Berardo, a Tebaldo, e a Guido del fu Crescenzio come a Pepone del fu Farulfo, il sacerdote Lupo, mantenendo il tono dispositivo, espose per iscritto e per inciso i quattro punti fondamentali e caratterizzanti la sua reggenza sulla chiesa; argomenti che esulavano dalla comune contrattazione notarile e che meglio potremmo vedere inseriti tra le delibere conciliari riformatrici dell'epoca. Facendo una separata stipulatio (...), sicuti sacra lex precepit, Lupo dichiarò di non avere la potestà necessaria su quella nuova istituzione per stringere qualsiasi contratto con monasteri o canoniche in mano ad abati e vescovi, obbligando così se stesso e i suoi successori a mantenere libera la piccola chiesa di Santo Stefano di Collescipoli come i suoi ministri ${ }^{66}$, perché quella chiesa era in quel momento "libera" e tale sarebbe dovuta rimanere anche in forza di quanto era stato concluso nel contractus dettato poco prima dai laici. Venne inoltre fissata anche in questo caso una pena pecuniaria corrispondente a dieci lire di monete di Pavia, ovvero a quell'abitudinaria penalità corrispondente alla dupla prevista in caso di evizione qualora non avesse avuto documenti che comprovavano il suo diritto ad alienare; nel caso di un mancato risarcimento della pena venne quindi previsto l'allontanamento del reo dall'ufficio ecclesiastico e si fissarono le modalità qualora fosse nata l'esigenza di una nuova nomina sacerdotale sulla base di quanto avevano stabilito i canoni, che a quella data, ricordiamolo, prevedevano per le ordinazioni regolarità ed estraneità rispetto a posizioni scismatiche e di scomunica del clero ordinante. Una nuova nomina sacerdotale sarebbe dovuta dunque venire solo dal vescovo ${ }^{67}$.

In chiusura della stipulatio di Collescipoli, espressione diretta e forte dell'esigenza riformatrice del momento, Lupo riservò a sé e ai suoi successori di poter stringere liberamente, e con finalità migliorative per quella chiesa, contratti di enfiteusi; quindi, anche il secondo "contractus" venne sottoscritto dai cinque testimoni già citati nella precedente carta di donazione, ciascuno dei quali in questo secondo testo dichiarò: scribere rogavi. Come nel documento precedente "Benincasa Dei nutu interveniente notarius et advocatus" diede efficacia probatoria al breve con il suo complevit et absolvit finale; mentre mancò anche in questo do-

confermativa o recettizia, cfr. Bertolini, 1905, p. 78; Leicht, 1933, p. 214.

${ }^{66}$ Nella seconda epigrafe rr. 14-28.

${ }^{67}$ Cfr. Lucioni, 2011, pp. 30-31. Già i canoni conciliari del 1083 di Gregorio VII, a noi giunti per tradizione indiretta, affrontarono diversi punti riguardo al rapporto tra laici e religiosi soffermandosi soprattutto sull'ordinazione di questi ultimi (cfr. Violante, 1972, pp. 3-67, alla nota 73, pp. 39-40 e testo corrispondente). Toccò poi ad Urbano II ritornare molte volte, anche in modo specifico, sull'ordinazione di chierici ordinati "a pseudo episcopis": cfr. Lucioni, 2011, nota 28 pp. 30-31 che segnala a questo proposito Matzke, 2002, pp. 1428, pp. 258-259; Kuttner, 1980, pp. 69-76; Rolker, 2010, pp. 92-100. La lettera di Urbano II al vescovo di Bologna si legga in Savioli, 1784, n. 83, p. 138; e si veda il commento storico di Benati, 1997, I, pp. 77-78. 
cumento il signum del prete Lupo nonostante egli avesse agito in prima persona.

\section{Conclusioni guardando a un'auspicata "libertas ecclesiae"}

A questo punto non possiamo che lamentare la distruzione degli atti originali. La loro trasformazione nell'unico, seppure interessante, stato epigrafico impedisce di arrivare a tutti quegli elementi intrinseci, spesso utili a disegnare il contesto in cui gli stessi furono costruitio8.

La scarsità di notizie al riguardo rende ovviamente problematica in primis qualsiasi spiegazione sulla mancanza, in entrambe le epigrafi, delle sottoscrizioni degli attori, fatto, crediamo, da non doversi risolvere imputando alle iscrizioni un valore diverso da quello del documento originale ${ }^{69}$. Rispetto a quelle mancanze saremmo allora più propensi ad immaginare che le due iscrizioni di Collescipoli finora analizzate rispecchino, a loro modo, l'attività notarile di un'epoca segnata dal passaggio "dalla charta all'instrumentum", quando la publica fides di professionisti capaci di conformarsi alle diverse realtà contestuali si muoveva oramai con destrezza tra prassi diverse prediligendo quelle che potevano meglio corrispondere ai negozi presentati alla loro perizia. E la mancanza delle sottoscrizioni degli attori nelle iscrizioni di Collescipoli potrebbe allora essere spiegata pensando alla stesura di contratti abbozzati "a tergo", rielaborati e stilati agevolmente in tempi e luoghi diversi dalla loro conclusione e non sempre alla presenza degli interessati che comunque, stretto il "negozio", si sentivano oramai garantiti dalla piena responsabilità e autorità del notaio, che nel caso di Collescipoli sappiamo essere stato nominato anche avvocato del nuovo ente ecclesiastico ${ }^{70}$. I testimoni che leggiamo sottoscrivere e chiedere la rogazione della stipulatio possono essere stati, pertanto, non i veri spettatori all'accordo, ma più semplicemente dei garanti della genuinità dei contenuti redatti; magari precedenti enfiteuti in procinto di stendere nuovi contratti con Lupo o con i suoi successori $i^{71}$.

Se il contractus stilato dai donatori della chiesa di Collescipoli aveva efficacemente risposto all'urgenza di definire formalmente almeno una parte importante delle obbligazioni, per non dover far ricorso in futuro, come espressamente venne detto nella prima epigrafe, al placito regalis vel apostolicas, venne dalla prassi romana lo spunto per la redazione della stipulatio di Lupo volta a garantire i donatori circa tutti quei punti importanti ed estranei all'atto di donazione difficilmente inseribili in una charta come salvaguardabili da qualsiasi norma del

\footnotetext{
${ }^{68} \mathrm{Nel}$ corso di questo lavoro è stata fatta un'ulteriore ricerca negli archivi locali degli originali pergamenacei nonostante la rarefazione documentaria di quel territorio sia da tempo nota. Un panorama della documentazione superstite e dello stato in cui trovava l'archivio capitolare di Narni si deve a Hagemann, 1974.

${ }^{69}$ Angelelli, 1995, p. 98.

70 Manaresi, 1937, p. 79; Bougard, 1995, pp. 264-269; Grossi, 1957, pp. 141-160.

${ }^{71}$ Bonfante, 1932, p. 341.
} 
diritto, e che trovarono allora in una simulazione del breve lo sfondo più consono e utile a placare anche i probabili timori notarili verso chi avesse avuto intenzione di mettere le mani su quella chiesa.

Di fatto se rivolgessimo ancora qualche attenzione alla documentazione raccolta tra le carte dell'abbazia di Farfa, e in modo particolare ai documenti rogati tra il 1091 e il 1092, troveremmo una refuta redatta proprio dallo stesso notaio Benincasa che potrebbe spiegare ancora meglio le scelte fatte più tardi a Collescipoli.

La notitia recordationis, refutationis et principalis renuntiationis, qualiter omni tempore in memoria retineatur ${ }^{72}$ strappata al vescovo Rodolfo di Narni, nonché abate del monastero di S. Cassiano, parte perdente nella contesa con l'abate Berardo II di Farfa, chiuse un contenzioso nato attorno a una donazione promessa qualche tempo prima dal prete Pietro di Farisinda al monastero vescovile di S. Cassiano di Narni, fatto che ci riporta all'iscrizione di Lanfranco e alla probabile ingerenza del monastero benedettino di S. Simpliciano di Milano. In quell'occasione, il prete di S. Cassiano aveva probabilmente ottenuto in beneficio personale alcuni immobili dal monastero narnense che indistintamente, assieme a tutte e tante altre sue proprietà, sarebbero poi passati all'abbazia di Farfa, vera e ultima beneficiaria del presumibile largo lascito sacerdotale grazie a un definitivo, secondo e finale atto di donazione redatto a suo vantaggio dallo stesso prete in punto di morte. La refutatio in jure della parte perdente al tempo rappresentava forse la prassi più quieta per risolvere una causa giudiziaria già dall'inizio persa, soprattutto se la parte avversa era una delle grandi abbazie del Regnum; perciò se da un lato la refuta del vescovo Rodolfo stilata dal notaio Benincasa, in modo formalmente similare a quanto Benincasa avrebbe stilato più tardi a Collescipoli, segnò negativamente l'economia della mensa monastica narnense, che si vide privata di un importante introito, dall'altro lato quella rinunzia vescovile salvaguardò, nel migliore dei modi, il monastero vescovile dalla perdita dei beni assegnati qualche tempo prima in beneficio al prete di Narni, dietro solenne e scritta promessa dello stesso vescovo, anche per parte dei suoi successori, che non sarebbe stato motivo alcuno per un ricorso, anche in futuro, al placito regali vel apostolicali aut in aliquo placito vel conventu aut extra placitum contro il monastero di Farfa. Di fronte alla forza della legge, alla potenza dell'abbazia sabina come alla completa e probabile perdita della donazione, nonché dei beni del monastero vescovile, perché questo sarebbe potuto accadere se il grande monastero di Farfa non fosse sceso ad un accordo sui beni di S. Cassiano, la refuta assicurò positivamente la conclusione di un'azione intentata a Farfa probabilmente dallo stesso vescovo e abate Rodolfo, che sappiamo essere stato appoggiato in quel momento dalla maiorum parte monachorum eiusdem monasterii, rimanendo, per noi, una forte e chiara testimonianza delle dinamiche vissute nella Sabina, territorio segnato, fino a quel momento, dalla voracità della grande abbazia.

Il contesto in cui si svolsero i fatti legati al monastero di S. Cassiano come quelli

${ }^{72}$ Giorgi, Balzani, 1879-1914, vol. V, doc. 1128, an. 1091 o 1092. 
connessi all'offerta della chiesa di Collescipoli e al prete Lupo è dunque quello dei tanti cambiamenti della seconda metà del secolo XI. Quello dell'ormai avviata riforma ecclesiastica, che impresse nei vescovi l'importanza di un veloce recupero istituzionale delle Eigenkirchen fondate sui diversi territori, nel nostro caso in quello castrense; quello dei grandi concili del 1083 di Gregorio VII e del più importante del 1089 di Melfi di Urbano II, i cui canoni si estesero sull'incompatibilità delle investiture laicali come sul ridimensionamento e su una necessaria involuzione della forza politica e istituzionale delle abbazie del Regnum, segnando nello specifico la fine nel territorio della Sabina della fase di constructio Farfensis ${ }^{73}$; come quello di una sempre più sentita e riformata libertas ecclesiae, elementi tutti, e ai quali se ne potrebbero aggiungere anche molti altri, di un contesto che spiega bene le cautele dimostrate da una figura come quella di Benincasa, che si titola notaio e avvocato, figura sicuramente più addentro di quanto si possa provare alle questioni ecclesiastiche ${ }^{74}$, chiamato a Collescipoli a comporre la delicatissima questione di una fondazione e di un'ordinazione sacerdotale laica pur nell'ammissione dell'importanza dei canoni e della riforma.

Dove concili e riforma non riuscivano ancora a sanzionare la vita ecclesiastica veniva dunque il diritto. Incidere e apporre le due epigrafi con il loro dettato confezionato con sapienza giuridica, sulla facciata dell'unica chiesa di quell'incastellamento, fondata nell'adempimento della vita canonicale e pastorale, tanto sospirata dalla riforma vescovile, dovette suggellare pubblicamente e monumentalmente, propagando, ciò che una documentazione manoscritta, per quanto studiata ed efficace, non avrebbe potuto fare abbastanza.

\footnotetext{
${ }^{73}$ Toubert, 1973, II, segnatamente alle pp. 883-885.

${ }^{74}$ Sulla figura dei cultori della giustizia e del notariato durante l'Alto Medioevo si preferisce rimandare alle importanti pagine di Bougard, 1995, pp. 347-371. Non sono molti i casi in cui la documentazione su cui ci siamo imbattuti offre esempi di figure le cui mansioni e titolature corrispondano a quella di notaio e avvocato ricoperte dal Benincasa ricordato sulle epigrafi di Collescipoli e che a nostro avviso è da intendersi un religioso dato l'inserimento di quel Dei nutu inciso nell'escatocollo. Tra le epigrafi e i documenti conosciuti sono, comunque, almeno due i casi in cui un religioso, il vescovo di Tortona Giseprando e l'arcivescovo di Pisa Carolus, si dicono rispettivamente "notarius et cancellarius" e "presbiter atque notarius" mentre la titolatura di advocatus al momento si lega al solo Benincasa.
} 


\section{Appendice documentaria}

1. Biblioteca Comunale degli Ardenti di Viterbo, perg. 2, 1080, dic. 13.

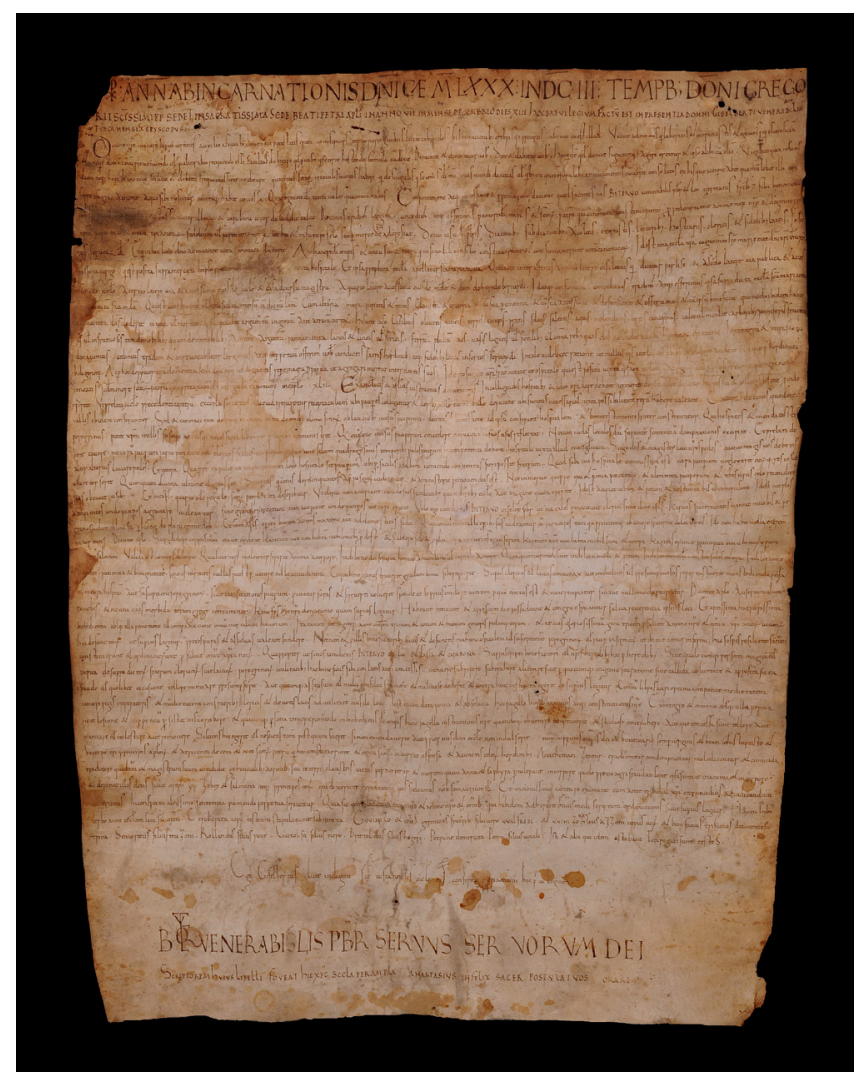

Fig. 1: Biblioteca Comunale degli ARdenti di Viterbo, PeRg. 2, 1080, Dic. 13

SI RINGRAZIA LA BIBLIOTECA CONSORZIALE DI VITERBO PER L'AUTORIZZAZIONE ALLA PUBBLICAZIONE DELL'IMMAGINE

1080, dicembre 13

Il prete Biterbo, Leone suo fratello, la madre Sassa e la moglie di Leone, Carabona, donano la Chiesa di S. Maria Nova, per farne una canonica per la salvezza delle loro anime e di quelle dei loro parenti, alla presenza del vescovo di Toscanella Giselberto che conferma e avalla la donazione.

(C) Anno ab incarnationis dominice MLXXX, indic(tione) III, temporibus Domni Gregorii sanctissimi Pape, sedet in sacratissima Sede beati Petri Apostoli in anno VII, in mense decembrio, dies XIII, hoc brevilegium factum est in presentia domni 
Giselberti venerabilis Tuscanensis episcopus.

Divine gratie munere, superne virtutis auxilio, a faucibus demoniace potestatis eruti, ut misericors eterne patrie gaudis faciat coheredes, scilicet monitionibus crebrisque preceptis informet, ut est illud; " Venite ad me omnes qui laboratis et onerati estis, et ego vos requiescere faciam " (Mt.,11,28). Et ne quis de via ad Eum perveniendi vel qualiter ab Eo recipiendi esse facultas dubitare quod promisit, ipse certe ostendit formula, cum dixit : " Dimitite, et dimittetur vobis, date et dabitur vobis » (Lc, 3,37-38). Hoc quidem quod docuit signiter quis agere ortatur et ipse alibi, cum dicit : "Vigilate quia nescitis diem neque horam ». (Mt. $25,13)$. Hanc vocem scilicet omnis debeat frequentissime meditare, quatinus semper pre oculis mentis habere qui de singulis qui se omnipotentis Dei misericordia hujus mundi divitias, vel quibus enim qui temporalibus adiuvamentis noverit consolatos, ex his, que acciperit ab Eo quantumlibet illi conferre cum gratiarum actione, a quo sibi noscitur cuncta que habet concessa, quia regnum Dei tanti valet quantum habes ${ }^{75}$. Confirmatione atque concessione et perpetua recordatione quod facimus nos Bitervo, venerabilis presbiter, et Leo germanis fratribus et filii bone memorie lohannis (eiusque eredes) et Sassa mater illorum et Carabona uxor de jamdicto Leo, donamus, tradimus, largimur, concedimus atque offerrimus, pro amore Dei omnipotentis et sanctorum patrum qui canonicam constituerunt, pro redemptione anime meę, nostrę et de genitore nostrum, verum etiam et omnium christianorum fidelium vel parentorum nostrorum, ut hic et in futuro seculo semper mercedem adcrescat, donamus vobis, presbiteris, diaconibus, subdiaconibus, acolitis, exorcistis, lectoribus, hostiariis, clericis et fidelibus laicis, in servis servorum Dei. Et qui in hoc loco, Domino adiuvante, vitam canonicam duxerit, ad honorem Dei omnipotentis et omnium sanctorum patrum, qui in sinodali consilio constituerunt et confirmaverunt vitam canonicorum : id est una ęcclesiam nostram cognomento sanctę Marię Matris Domini nostri lesu Christi piissima Virgo qui est posita supra mercatu de ipso prenomine [...] juxta hospitale. Et ipsa prephata ęcclesia appellatur Sancta Maria Nova, qui iacet inter affines: a primo latere casa Leonis qui dicitur Parlise et a secundo latere via publica et accessio idem ęcclesie; a tertio latere via et accessione eiusdem ecclesie et casa di Ursu magistru; a quarto latere accessione eiusdem ecclesie et domus de herede Bernardi. Ideoque confirmamus, concedimus, tradimus atque offerimus ipsa supradicta ecclesia $\mathrm{S}$. Maria Nova [ad ca]nonicam faciendam, qui est constructa vel hedificata in ipsum iamdictum locum cum altaria, mura, parietis et tectis, claustra et oratoria et cum sua pertinentia et cum sua accessione et defensione et offertione et cum ipsum beneficium que modo ibidem habet vel in antea Dominus dederit, vivorum vel mortuorum, vel qualibet argumentum, ingenium aut atramentum cartarum; hi sunt case, casalinis, olivetis, vineis, terris, campis, pratis, silvis, salectis, aquis, molendinis, ortis, canapinis, culte vel inculte, arboribus pomiferis fructuosis vel

\footnotetext{
${ }^{75}$ Manca l'avverbio ideo/ideoque.
} 
infructuosis, tam de mobilibus quam de immobilibus, aurum, argentum, pannamenta, laneis et lineis vel siricis, ferrum, plu<m>bum, aes, vasis ligneis vel fictilibus, vel omnia rebus quas Dominus condidit ad usum humanarum creaturarum, in integrum et in transactu donavimus, cedimus, tradimus et inrevocabiliter largimus atque in perpetuum offerimus vobis iamdictis sancti hordinibus atque fidelibus laicis in servis servorum Dei, in tale videlicet ratione, ut nullus episcopus aut laycus ibi prior eligere audeat nisi quem prehordinati heligerint. Ac per hoc deprecor vestra clementia, karissimi domini mei, ut dignetis recipere magna pro parva ut agregari merear inter electos suos. Idcirco sugero vestram fraternitatem ut ospitale, qui est positum iuxsta ipsam ecclesiam, ad regimen vel ad susceptione peregrinorum teneatis secundum more sanctorum patrum, qua pretaxatum est in regula canonicorum in capitulo XLII. Evangelicis et apostolicis instruimus documentis in colligendis hospitibus et ideo opera<m> dare debent ut merito de nobis a Deo dicatur: "Hospes fui et collegistis me " (Mt. 25,35). Proinde oportet ut prelati ęcclesie, precedentium patrum excempla sectantes, aliquid preparetur receptaculum ubi pauperes colligantur et de rebus ecclesie precedentium patrum excempla sectantes aliquid preparetur receptaculum ubi paupers colligantur et de rebus ęcclesie tantum ibidem deputent, ubi sumtus necessarias iuxta possibilitatem rerum habere valeant, exceptis decimis, que de ecclesie villis ibidem conferuntur. Sed et canonici tam de frugibus quam etiam de omnibus elemosinarum oblationibus in usus pauperum decimis libentissime ad ipsum conferant hospitalem, et boni testimonii frater constituatur qui hospites et mendicos stes[...] peregrinus putet Christum, in illis suscipiat, eisque necessaria libenter pro viribus administret; que namque in usus pauperum concedere a quaqua ${ }^{76}$ in suos usus reflectat, ne cum luda loculos Domini furantem sententiam damnationis excipiat. Et prelati debent cavere nec curam pauperum parvi pendant et clericis, si aliis temporibus ibique sunt nequeunt, saltim quadragesimis temporibus pedes pauperum in competenti debent hospitali <lavare> iuxta illud evangelicum : " Si ego dominus et magister lavi vestros pedes, quanto magis vos debetis alter alterius lavare pedes " (Giov. 13,14 ) et cetera. Quapropter expedit ut in competenti loco hospitale sit pauperum ubi perfacilis ad illud veniendi conventus fieri possit fratrum. Quod sibi cui hospitale commissum est cura pauperum neglexerit eorumque res in suo usu retorserit quamquam divina ulsione dignus sit severius quam cecus derelinquentes a prepositis iudicetur et a ministerio removendus est, nec inmerito, quippe qui et premia peccatorum et alimenta pauperum et thes<a>urus celo reconditus suis obtavit usibus. Et in capitulo quarto idem regule sanctorum patrum ita describitur: ut clerici non accipiant tam de suis facultatibus quam de rebus ecclesie aut exigant quam <plus> opportet. Id est acipiat cibum et potum et vestimentum, his contempti sunt - id est nec plus accipientes unde pauperes aggravare videantur sine grande peccatum non accipiant unde pauperes victuri erunt. Volo ego

\footnotetext{
${ }^{76}$ Forse ac nequaquam?
} 
iamdictus Bitervo, infelix presbiter, ut ita tales permaneant clerici sicut dicit apostolus: "Karitas fraternitatis maneat in vobis et peregrinos nolite oblivisci " (Ebr. 13). Per hanc quidam placuerunt Deo.- Et item apostolus : "Operemur bonum ad omnes, maxime autem ad domesticos fidei". Quia quamvis nonulli operibus sanctis videantur esse participes, tamen, quia privantur ab amore fraterne dilectionis, ideo non habent ulla incrementa, virtutis, dicente apostolo : "si tradidero corpus meum ita ut ardeat, karitatem autem non habeam, nihil michi prodest. Et si abuero fidem et prophetiam, ut montes transferam, karitatem autem non habeam, nihil sum» et cetera (1 Cor., 13). Karitas optinet principatum omnium bonorum operum, dicente Salomon : «Valida est ut mors dilectio» (Cant, $8,6)^{77}$ : Quia sicut mors violenter seperat animam a corpore, ita dilectio Dei separat hominem a mundano vel carnali amore. Quia quattuor modi sunt in dilectione Dei et proximi. In dilectione Dei constat fides et opera. In dilectione proximi patientia et benignitate. Sine as virtutes nullus potest pervenire ad beatitudinem. Et qui bene ministraverit gradum bonum sibi requirit. $\mathrm{Si}$ quis clericus vel laicus contumax aut inobediens vel presumptuosus repertus fuerit in custodienda regula, vel in cura hospitum aut susceptione peregrinorum, sive in visitationes pauperum, proiciatur foras et si reverti voluerit spondeat se prius emendare vitium pro quo eiectus est, et tunc recipiatur, sin autem, nullo modo recipiatur, dicente apostolo: "Auferte malum ex vobis, et ne una ovis morbida totam gregem contaminet". Karissimi fratres hęc nostra donatione, quam superius legitur, habeant, teneant et a presenti die possideant et congrue fruantur, salva reverentia ipsius loci et aptissima ac purissima hobedientia, absque ulle remotione vel contradictione omnium mortalium hominum; ita tamen ut iugiter a Deo omnipotentem trinum et unum et humani generis redemptorem et ad Eius gloriosissimam genitricem pro salutem anime nostre et omnium Christianorum vivorum hac defunctorum ut superius legitur preces puras et assiduas valeant fundere, nec non et pro illis benefactoribus vivis et defunctis qui hunc hospitalem ad susceptionem peregrinorum vel pauperum infirmorum ut ibi tueantur infirmi hac sospes resilient sanati ${ }^{78}$ constituerunt vel ordinaverunt pro salute omnium christianorum. Quapropter, ut si nos iamdictis Bitervo et Leo et Sassa et Carabona, suprascripti benefactori, vel nostris heredibus hac proheredibus sive qualecumque persona magna vel parva de supradictorum fratrum clericorum sive laicorum, peregrinorum utilitationibus hac beneficiis sibi conlatis atque concessis minuere, subripere, subtrahere, alienare, sive pro quocumque ingenio seu ratione sive callida voluntate et apposita ficta fraude vel qualibet occasione tollere, minuare presumpserit aut quicumque assensum vel malum consilium studiose et malitiose dederit et contra hanc instituta egerit, ut superius legitur, centum libras auri optimi componat, medietatem camere regis imperatoris et medietatem confratribus, clericis et devotis laicis ad utilitatem

\footnotetext{
77 "Fortis est ut mors dilectio"

${ }^{78}$ Sopra la sillaba finale c'è un segnetto abbreviativo che non capisco
} 
eiusdem loci. Post etiam data pena et absoluta hęc pagella hordinationis atque constitutionis nostre, ex integro et omnino absque ulla permaneat lesione et in perpetuum persistat in suo robore et quacumque persona, temerario modo inhobediens Dei omnipotentis, hanc pagella institutionis nostre quandoque obvenire temptaverit et studiose contrahere, aut que concessa sunt tollere aut minuare vel molestare aut removere, si sciens hoc egerit vel nesciens, tamen postquam scierit si non emendaverit aut prior eiusdem ecclesie non indulserit tunc inprimis omnipotentis Dei et beate Marie semper virginis et beati lohannis Baptiste et beati Petri principis apostolorum et a tricenti decem et octo sanctorum patrum qui hoc constituerunt et omnium sanctorum occurrat offensa et a cunctis celorum hordinibus anathemizentur, eradicentur, condempnentur, maledicentur et cum luda traditore qui dominum et magistrum suum vedidit gehennalibus, atrocibus, seu teterri<mis> claustris victus participetur, et mortem quam Anna et Saphyra pertulerunt in corpore, qui de pretio agri fraudati sunt, ipsa sentiat in anima et in corpore et deponat illos Deus sicut Oreph, Zep, Zebeę et Salmana atque principes eorum qui dixerunt hereditatem possideamus nobis sanctumarium Dei et in novissimo venturo examine, cum ante tribunal Christi eterni iudicis ad iudicandum exierimus in conspectu Altissimi, sententia puniendi perpetua feriantur. Quia sic complacuit animo nostro ${ }^{79}$ et animo nostro et omnibus qui ibidem adherant huiusmodi scriptum ordinationis sicut superius legitur. Hactu in Biterbo ante ecclesiam Sanctum Silvestrum. Et robora coram testium stipulatione subnixa. Gvvinizo et loannes germanis fratribus, filii vero Vvalfredi et Vvinizio filius Azzoni nepus eorum et Bonifatius tribunus de civitate Sutrina, Senioritus filius Teuzoni, Rollandus filius Ricce, Liutolfu filius Nero, Brittaldus filius Hogeri, Petrune de Mercatu, Petru filius Vitali. Isti et alii, qui ibidem astabant toti rogati sunt testes.

Ego Giselbertus licet indignus sanctę Tuscanensis ecclesie episcopus confirmo propria manu hoc privilegium.

(Monogramma di Bitervo) Venerabilis presbiter servus servorum Dei.

Scriptorem huius libelli foveat hic Christus secla per ampla. Anastasius infelix sacerdos postulat vos orare.

${ }^{79}$ Segue animo nostro erroneamente iterato 
2. Charta lapidaria di S. Maria Nova, a. 1080. Chiesa di S. Maria Nova di Viterbo, In cornu epistulae.

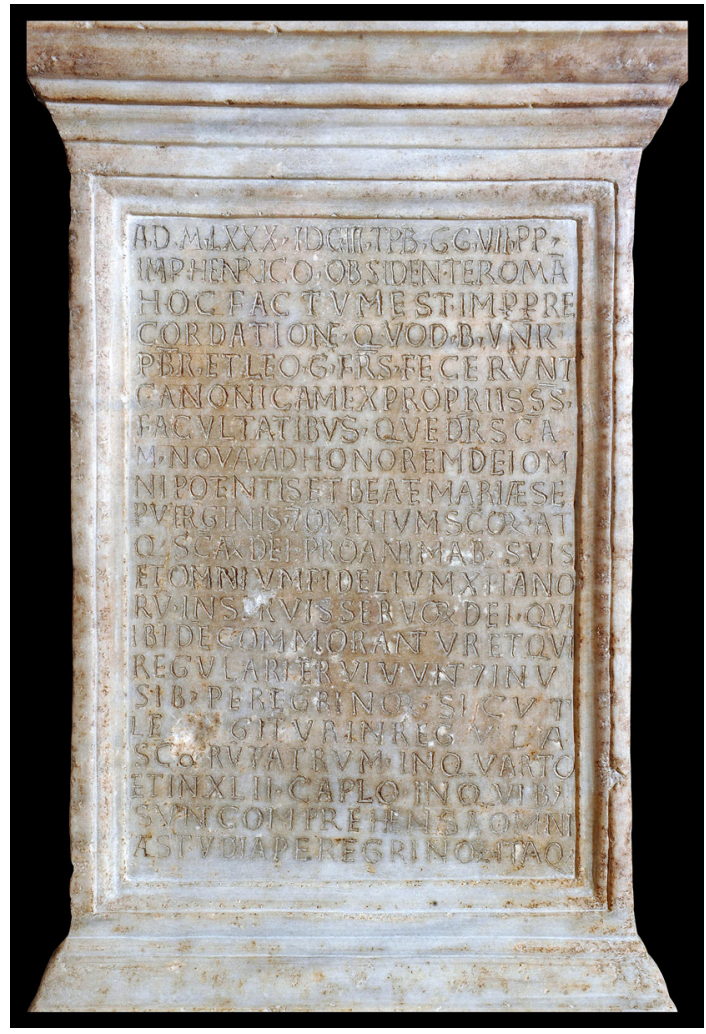

FIG. 2: Charta lapidaria DI S. Maria Nova, A. 1080. Chiesa DI S. MARIA Nova DI VITERBO, IN CORNU EPISTULAE (IMMAGINE DELL'AUTORE)

\section{prima faccia}

A(nno) D(omini) M LXXX i(n)d(i)c(tione) III T(em)p(ori)b(us) G(re)g(orii) VII p(a)p(e) || imp(erator) Henrico obsidente Roma(m) || hoc factum est imp(er)p(etuum) re || cordatione quod B(iterbus) v(e)n(e)r(abilis) || p(res) $b$ (iter) et Leo g(ermani) $f(r a t) r(e) s$ fecerunt || canonicam ex propriis $s(u i) s||$ facultatibus que d(icitu)r s(an)c(t)a || M(aria) Nova ad honorem Dei om || nipotentis et beate Mariae se(m) $\| p(e r)$ Virginis . et omnium $s(a n) c(t) o r(u m)$ . at || q(ue) $s(a n) c(t) a r(u m)$ Dei. pro animabus suis || et omnium fidelium (christi)ano || rum in servis servor(um) Dei qui || ibide $(\mathrm{m})$ commorantur et qui || regulariter vivunt et in $u$ || sius peregrinor(um) sicut || legitur in regula || $s(a n) c(t) o r u(m)$ patrum in quarto $\|$ et in XLII cap(itu)lo in quib(us) I| sunt comprehensa omni || a studia peregrinor(um). itaq(ue) 


\section{seconda faccia}

sagacissimus B(iterbus) sac(erdos) et || Leo g(ermanus initoq(ue) consilio || una $\mathrm{cu}(\mathrm{m}) \mathrm{Gselb}(\mathrm{er})$ to e(pisco)po $\mathrm{S}(\mathrm{an}) \mathrm{c}(\mathrm{t}) \mathrm{e}$ || (uscaniensis) ecle(sie) volumus $\mathrm{n}$ (ost)ra dona || tione in tale videlicet ra || tione ut nullus e(pisco)p(u)s aut la || icus priore ibi eligere || audeat nisique $p(r e)$ ordi || nati heligerint et ta || I[is] persona eligatur || que benevaleat ad cultu(m) || canonice vel ad suscep || tione $(m)$ peregrinor(um). Si $q(u i) s||$ hoc statutu $(m)$ frangere || voluerit aut de propri || etate huius eccle(sie) studi || ose defraudare et prior || eiusde $(m)$ ecclesie non indul || serit $t(u n) c$ in primis om(ni)p(otent)is || $D(e) i$ et beate $M($ arie) se(m)p(er) Virg(inis) et o(mn)ium || $s(a n) c(t) o r(u m)$ anahtema sit sicut || Anna et Saphira et luda q(ui) || D(eu)m tradidit ante tribunal || Christi. Ego G(iselbertus) e(pisco)p(u)s T(uscaniensis) ecclesie || c(on)firmo hunc p(ri)vilegium.

\section{terza faccia}

Nos vero $q($ ui) inchoavimus || hanc eccl(esi)a(m) ta(m) grata ope || ra designamus $\mathrm{n}$ (ost)ra no $\|$ mina $\mathrm{B}$ (iterbus) ven(erabilis) $\mathrm{p}$ (res)b(ite)r et Leo et Sas || sa mat(er) n(ost)ra et Carabona || uxsor Leonis ideoq(ue) ob II nixe rogamus $v$ (est)ram fra $\|$ ternitatem om(ni)b(us) $q(u i)$ in hoc loco sunt preordinati ut $\| \mathrm{n}(\mathrm{ost}) \mathrm{ru}(\mathrm{m})$ hobitum memoriter te || neatis q(uia) dignu(m) est hii q(ui) tam || mirificu(m) opus inchoaverunt $\|$ ut se(m)p(er) memorialem hobitum || habeant in missis et psalmis || et in largis helemosinis $q($ uod) si || hoc dignius non esset anni || versariu(m) a $S(a n) c(t)$ is Patrib(us) con || stitutu(m) non fuiset $\mathrm{D}(\mathrm{eo})$ gra(tia)s || VIII Id(us) Nob[embris] obitu Sassa || XIIII K(alendas) Dec(embris) obitu Leonis || amatore huius canonicae plusquam phi || lios aut philias [et Nonis lanuarii obitu Pretie filie eius]. 


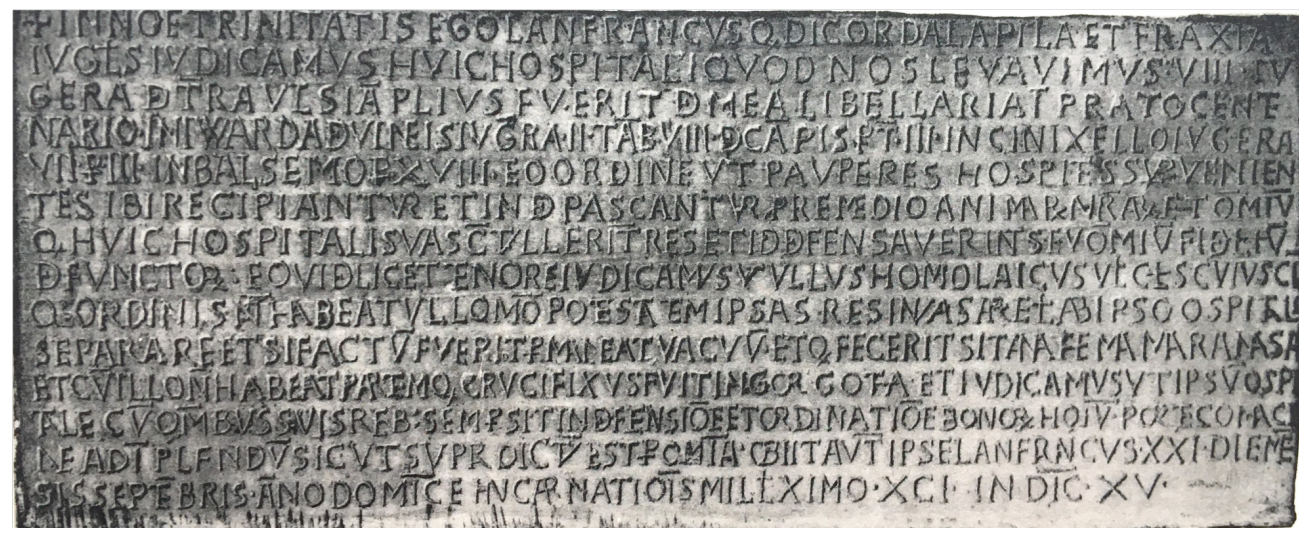

FIG. 3: ChaRta LAPIDARIA DI LANFRANCO E FRAXIA, A. 1091.

ORIGINALE SMARRITO; FOto IN SilvagNI, 1944, VOL. II. FASC. MEdiOlanUm, TAV. VI

+ In no(min)e Trinitatis. Ego Lanfrancus q(ui) dicor da la Pila et Fraxia || iug(a) I(e)s iudicamus huic hospitali quod nos levavimus VIII iu I gera de t(er)ra v(e) I si a(m)plius fuerit de mea libellaria i(n) Prato Cente ||nario i(n) Niwarda de vineis iug(e)ra II tab(vlas) VIII, de ca(m)pis p(er)t(icas) III, in Cinixello iugera II VII p(erticas) III; in Balsemo p(erticas) XVIII. Eo ordine ut pauperes hospitae sup(er)venien || tes ibi recipiantur et inde pascantur $p(r o)$ remedio animar(um) $\mathrm{n}$ (ost)rar(um) et om(n)iu(m) || q(ui) huic hospitali suas c(on)tulleri(n)t res et id defensaverint seu om(n)iu(m) fideliu(m) || defunctor(um), eo videlicet tenore iudicamus ut ullus homo laicus v(e)l cl(ericu)s cuiuscu(m) || q(ue) ordinis $n(o n)$ habeat ullo mo(do) potestatem ipsas res invasare v(e)l ab ipso ospitali || separare et si factu $(m)$ fuerit $p(e r) m a n e a t ~ v a c u u(m)$ et $q(u i)$ fecerit sit anathema maranasa II et c(um) illo $n$ (on) habeat partem qui crucifixus fuit in Gorgota. Et iudicamus ut ipsu(m) ospi || tale c(um) om(ni)bus suis reb(us) semp(er) sit in defensio(n)e et ordinatio(n)e bonor(um) ho(m)i(n)um porte Comaci || ne ad i(m)plendu(m) sicut supradictu(m) est $p(e r)$ om(n)ia. Obiit aut(em) ipse Lanfrancus XXI die me(n) || sis septe(m)bris, a(n)no domi(ni)ce incarnatio(n)is mill(e)ximo xci, indic(tione) $x v$.

Latuada, 1737 - 1738, voll. I-V, V, n. 186, p. 85; Giulini, 1855-1857, II, pp. 588589. 
4. Archivio dell'Ospedale Maggiore di Milano, "Pergamene del secolo XI", n. 3

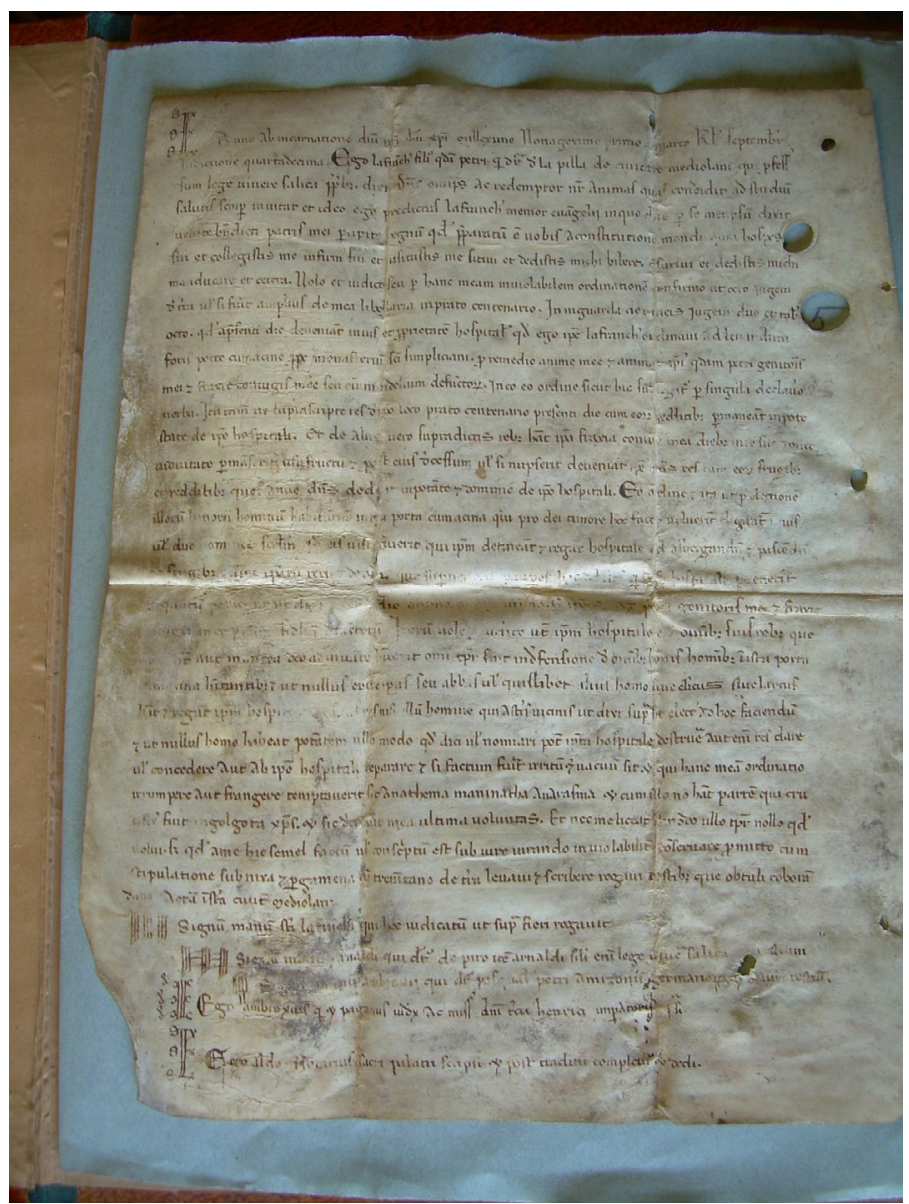

Fig. 4: Archivio deli'Ospedale Maggiore di Milano, "Pergamene del Secolo XI", N. 3. SI RINGRAZIA LA FondAZIONE IRCCS CA' GRANDA OSPEDALE MAGGIORE POLICLINICO PER L'AUTORIZZAZIONE ALLA PUBBLICAZIONE DELL'IMMAGINE

1091, agosto 29

Lanfranco del fu Pietro detto de la Pilla di Milano, di legge salica, istituisce e dota con il suo iudicatum, pro remedio della sua anima, di quella del padre Pietro, della moglie Fraxia e di tutti i fedeli defunti, un ospedale di cui ordina, nello stesso tempo, la costruzione fuori Porta Comacina, presso il monastero di S. Simpliciano di Milano. Per indicazioni l'ospedale sarà giuridicamente e amministrativamente affidato ai boni homines di Porta Comacina, che lo dovranno difendere da qualsi- 
asi intromissione ecclesiastica o laica. Dispone, inoltre, che tutto il resto dei suoi beni resti in usufrutto alla moglie Fraxia purchè mantenga lo stato vedovile. Atto rogato "in suprascripta civitate Mediolani".

(S) Anno ab incarnationis domini nostri lesu Christi. Milleximo nonageximo primo, quarto kalendas septembris, indictione quartadecima. Ego Lafranchus filius quandam Petri qui dicitur de la Pilla de civitate Mediolani qui professus sum lege vivere salica presentibus dixi: Dominus ominipotens ac redemptor noster animas quas condidit ad studium salutis semper invitat et ideo ego predictus Lafanchus memor evangelii in quo Dominus per semetipsum dixit: "venite benedicti patri mei, percipite regnum quod preparatum est vobis a constitutione mundi quia hospes fui et collegistis me, infirmus fuis et visitastis me sitivi et dedistis mihi bibere, esurivi et dedistis mihi manducare etcetera". Volo et iudico seu per hanc meam inviolabilem ordinationem confirmo ut octo iugera de terra vel si fuerit amplius de mea libellaria in Prato Centenario. In Niguarda de vineis iugera duo et tabulas octo quod a presenti die deveniant in ius et proprietatem hospitalis quod ego ipse Lafranchus ordinavi ad levandum foris Porte Cumacine prope monasterium Santi Simpliciani pro remedio anime mee et animarum ipsius quandam Petri genitoris mei et Fraxie coniugis mee seu omium fidelium defunctorum. In $\mathrm{eo}^{80}$ ordine sicut hic subtus legitur per singula declaravero verba, ita tamen ut suprascripte res de ipso loco Prato Centenario presenti die cum eorum redditibus permaneant in potestate de ipso hospitali. Et de aliis vero supradictis rebus habeat ipsa Fraxia coniux mea diebus vite sue donec viduitate permanserit in usufructu et post eius decessum vel si nupserit deveniant ipse omnes res cum eorum frugibus et redditibus quos annue Dominus dederit in potestate et domino de ipso hospitali. Eo ordine ita ut per electionem illorum bonorum hominum habitantium in ipsa Porta Cumacina qui pro Dei timore hoc facere voluerint eligatur unus vel duo homines secundum quod eis visus fuerit qui ipsum destineant et regant hospitale ad albergandum et pascendum de frugibus omnium ipsarum rerum et ominibus que supervenerint ad pauperes hospitali qui [in] suprascripto hospitali pervenient aliquantum [...] ut dixi est pro remedio anime mee et animarum ipsorum Petri genitoris mei et Fraxie coniugis mee et omnium fidelium defunctorum. Iterum volo et iudico ut80 ipsum hospitale cum omnibus suis rebus que annue habet aut in antea Deo adiuvante habuerit, omni tempore sint in defensione de omnibus bonis hominibus in ista Porta Cumacina habitantibus et ut nullus episcopus seu abbas vel quislibet aliu homo sive clericus sive laicus habeat et regat ipsium hospitale [vel sua] res nisi illum hominem qui a suprascriptis vicinis ut dixi supra sit electus ad hoc faciendum et ut nulls homo habeat potestatem ullo modo quod dici vel nominari potest ipsum hospitale destruere aut enim res dare vel concedere ab ipso hospitali separare et si factum fuerit irrituum et vacuum sit et qui hanc meam ordinationem irrumpere aut

8079 Segue eo erroneamente iterato. 80 Ut con segno abbreviativo. 
frangere temptaverit sit anathema maninata anarasma et cum illo non habet partem qui crucifissus fuit in Golgota Christus. Et sic decrevit mea ultima voluntas et nec me liceat nullo modo, ullo tempore nolle ${ }^{81}$, quod volui, sed quod a me hic semel factum vel conscriptum est sub iure iurando inviolabiliter conservare promicto cum stipulazione subnixa et pergamena cum trementario de terra levavi et scribere rogavi testibusque obtuli roborandam. Acta in suprascripta civitate Mediolani.

(S) Signum manum suprascripti Lafranchi qui hoc iudicatum ut supra fieri rogavit.

(S) Signum manum Arnaldi qui dicitur de Piro item Arnaldi filiu enim lege vivere salica testium.

(S) signum manum Ambroxii qui dicitur Pesqualis, Petri, Amizonis germanorumque et aliorum testium.

(S) Ego Ambroxius qui et Paganus iudex missus domini tercii Henricii imperatorii subscripsi.

(S) Ego Ado notarius sacri palatii scripsi et post traditum complevi et dedi.

Manaresi, Santoro, 1969, n. 765, pp. 392-394; Sommerlechner, 2010, pp. 176178.

\footnotetext{
${ }^{81}$ Scrive nolle per nollo.
} 
5. Archivio dell'Ospedale Maggiore di Milano, "Pergamene del secolo XI", n. 4.

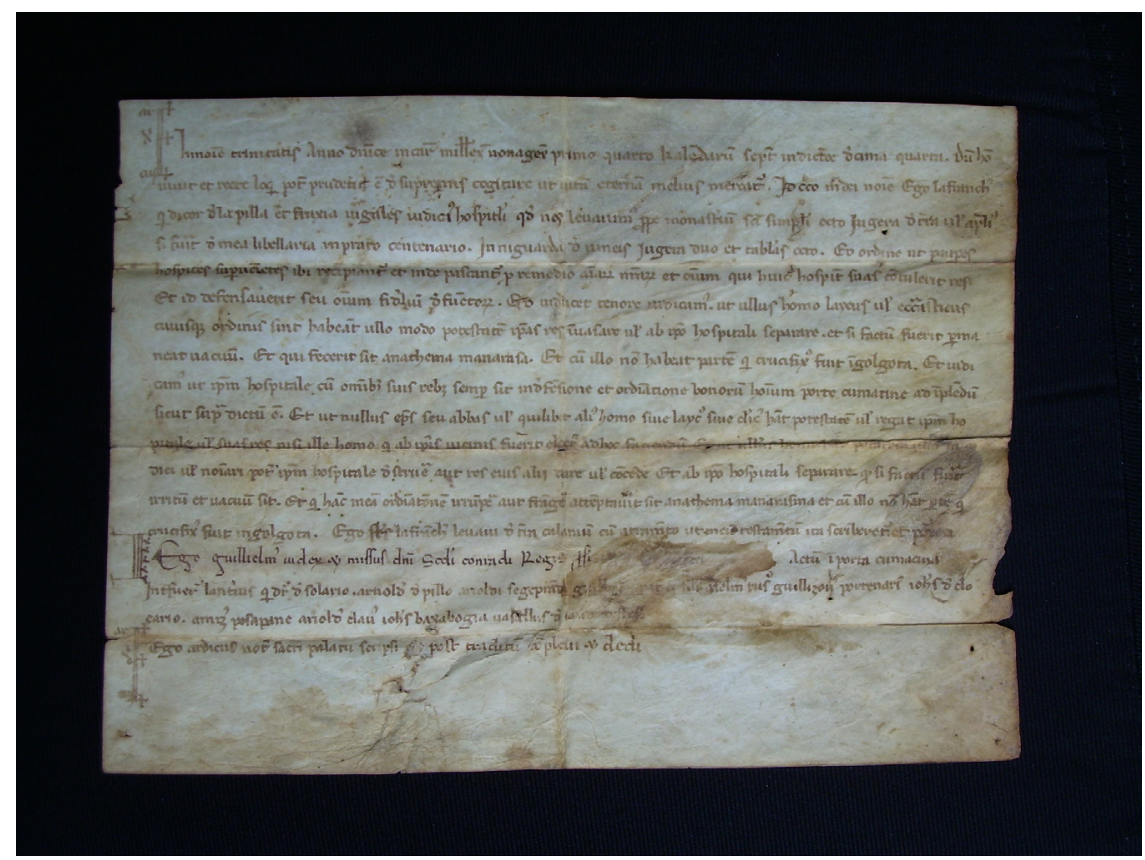

Fig. 5: Archivio dellóspedale Maggiore di Milano, "Pergamene del secolo XI", N. 4. SI RINGRAZIA LA FondaZIONe IRCCS CA' GRANDA OSPEDALe MAgGIORE POLICLINICO PER L'AUTORIZZAZIONE ALLA PUBBLICAZIONE DELL'IMMAGINE

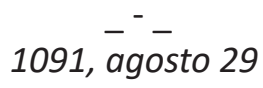

Lanfranco della Pilla e la moglie Fraxia istituiscono, dotandolo, un ospedale da costruire presso il monastero di S. Simpliciano pro remedio animarum loro e di tutti quelli che contribuiranno a difendere i beni di cui è stato dotato e per la memoria di tutti i fedeli defunti. Dispongono, inoltre, che l'ospedale sia giuridicamente e amministrativamente affidato ai boni homines di Porta Cumacina. Atto rogato a Porta Cumacina.

S. In nomine Trinitatis. Anno dominice incarnationis milleximo nonageximo primo, quarto Kalendas septembris, indictione decima quarta. Dum homo vivit et recte loqui potest, prudens est de supremis cogitare, ut vitam eternam melius mereatur. Idcirco in Die nomine ego Lafrancus, qui dicor de la Pilla, et Fraxia iugales iudicamus huic hospitali quod nos levavimus propre monasterii sancti Simpliciani, octo iugera de terra vel amplius si fuerit de mea libellaria in Prato Centenario, in Nivuarda de vineis iugera duo et tabulas octo, eo ordine, ut pauperes hospites supervenientes ibi recipiantur et inde pascantur pro remedio animarum nostrarum et omnium qui huic hospitali suas contulerint res et id 
defensaverint seu omnium fidelium defunctorum. Eo videlicet tenore iudicamus, ut nullus homo laicus vel ecclesiasticus, cuiusque ordinis sint, habeant ullo modo potestatem ipsas res invasare vel ab ipso hospitali separare et si factum fuerit permaneat vacum. Et qui fecerit sit anathema maranthana et cum illo non habeat partem qui crucifixus est in Golgotha. Et iudicamus ut ipsum hospitale cum omnibus suis rebus semper si in defensione et ordinatione bonorum hominim Portae Comacinae ad implendum sicut supra dictum est. Et ut nullus episcopus seu abbas vel qualibet alius homo sive laicus sive clericus habeat potestatem vel regat ipsum hospitale vel suas res nisi ille homo qui ab ipsis vicinis fuerit electus ad hoc faciendum et ut nullus homo habeat potestatem ullo modo, quod dici vel nominari potest, ipsum hospitali destruere aut res alius alii dare vel concedere et ab ipso hospitali separare, quod si factum fuerit, irritum et vacuum sit. Et qui hanc meam ordinationem irrumpere aut frangere attemptaveri, sit anathema manarasma et cum illo non habeat partem, qui crucifixus fuit in Golgota. Ego supradicto Lafranchus levavi de terra calamum cum atramento, ut meum testamentum ita scriberetur et porrexi.

Ego Guillelmus iudex et missus domini secundi Conradi regis [subscripsi]. Actum in Porta Comacina. Interfuerunt Lanterius, qui dicitur de Solario ; Arnold(us) de Pillo, Arioldi Segeprandi Guillelm(us) [...] pater et filii, Anselmus Rusus, Guillizonus Portendrius, lohannes de Clocario, Amizus Pesapane, Arioldus Clauus, Iohannes Baxabogia, Vasallus de [...] testes.

Ego Ardicus notarius sacri palatii scripsi et post traditum complevi et dedi.

Sommerlechner, 2010, pp. 176-178. 
6. Collescipoli, Chiesa di San Stefano, a. 1094. Chartae lapidariae. Sulla facciata della chiesa, a sinistra del portale. Colonne I-V.

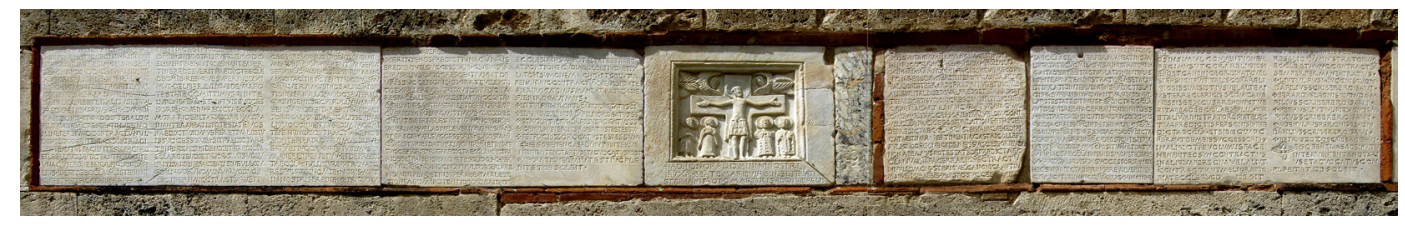

Fig. 6: Collescipoli, Chiesa di San Stefano, A. 1094. Chartae lapidariae. Sulla facciata DELLA CHIESA, A SINISTRA DEL PORTALE. ColonNe I-V (IMMAGINE DELL'AUTORE)

\section{Conctractus "cartula offersionis"}

Pepo e Bernardo, figli del fu Falcone; i fratelli Litaldo, Gualfredo e Bernardo, figli del fu Rapizone; Guido e Tebaldo, figli del fu Crescenzio, assieme a Pepone, figlio del fu Farulfo, consegnano pro animarum loro e dei loro parenti la chiesa di Santo Stefano costruita nel territorio del castrum di Collescipoli con tutte le sue pertinenze al prete Lupo, figlio del fu Crescenzio, e ai suoi successori, i quali dovranno risiedere nella chiesa avendone il pieno e libero possesso, garantendo in futuro di non reclamare, inoltre, anche a nome dei propri eredi, in sede di placito regale e apostolico, alcun diritto di patronato. Lupo, a nome anche dei suoi eredi, infine garantisce di difendere la chiesa e le sue pertinenze da qualsiasi molestia possa venire da loro stessi, dai loro eredi, come dagli estranei, sotto pena di cento soldi di moneta pavese e della maledizione divina.

+ In no(min)e Patris et Filii et $S p($ iritu)s $S(a n) c(t) i . ~ \| A b$ incarnatione d(omi) ni n(ost)ri le(s)u Christi || sunt anni millesimo nonagesim(o) || ter(tio), Enrico quonda(m) Enrici impe || ratoris filio reg(nante), XII kal(endas) mar(tii) || indic(tione) II. Profitens profitemur || nos Pepo et Bernardu<s> filii cuius || $\mathrm{da}(\mathrm{m})$ Falconis et litaldus et Gual || fredus et Bernardus ge(rma)n(i) cuiusda(m) || Rapizonis et Guido et Tebaldus || filii quonda $(\mathrm{m})$ Crescentii in Dei no || mine per hunc contractu(m) nul || lo nobis cogente neq(ue) contra ||cente aut vi(m) facente sed propria || et legali voluntate antecedente || una $c u(m)$ Pepone Farulfi quonda(m) fi || lius idest de ecclesia Sancti Stephani ||que est edificata infra perti ||nenia(m) castri Collescipuri cum || om(n)ib(us) suis dotalibus que modo || sibi pertinent aut que in antea per || tinere debuerint predicte ecclesie ||de om(n)ib(us) rebus que superius dixi $\|$ mus deliberavimus de $n$ (ost)ra po II testate com(m)ittimusq(ue) in te $\|$ Lupone $p(r e s) b(i t e) r o$ et in tuis succes || sorib(us) qui in predicta eccl(esi)a || morari debent quod ab hac hora || in antea abeatis potestate $(\mathrm{m})$ vos || predictus Lupus $\mathrm{p}(\mathrm{res}) \mathrm{b}($ ite $) r$ et in aliis tu || is successorib(us) sit predicta re || tenendi et possidendi et predicta || ec(c) 
I(esi)a regendi et q(ui)cq(ui)t vos volu || eritis ad benefaciendi sine ullo iu || go aliquoru $(m)$ hominu $(m)$ quod nos ||$p($ re)dicti per hunc $c(o n) \operatorname{tractu}(m)$ que ti

bi Luponi fecimus et in aliis tuis su || cessorib(us) in pro rede(m)ptione ani II me $n($ ost)re $n(o s t)$ roru(m)q(ue) parentu(m) in servi ||servoru(m) D(e)i que nos se(m)per permane $\|$ amus taciti et $c(o n) t e n t i$ quod nos nu(m) || quam queramus inde aliquo $(\mathrm{m})$ por || tione per nullo modo seu per ali ||quo ingenio nec per ullu(m) umanu(m) || sensu(m) q(ue) cogitare pote(st) in placi $\|$ to regalis vel ap(osto)licas seu in a || liquo conventu sed immo om(n)i || te(m) $\mathrm{p}$ (or)e hunc contractu(m) que nos || sponte fieri rogavimus impul || satu(m) et incorruptu $(m)$ iubemus per || manere in perpetuu $(m)$ et de predic || ta eccl(esi) a nullo iure patronato || reservato in om(n)ib(us) nobis aut || in nostris eredibus. Et si quoquo || te $(\mathrm{m}) \mathrm{p}$ (or)e aliquo persona hominu(m) insurre || xerit de nos predicti una cu(m) $n$ (ost)ris | eredib(us) vel successorib(us) que vos $p$ (res)b(ite)r || Lupus filius ${ }^{82}$ quod Crescentius aut de || vostris successorib(us) ex parte vel ex to || to expellere voluerit aut de predicta || res fac(er)e aliqua( $m$ ) molestia<m> tunc contra || o(mne)s homines antea stare et difendere una || $\mathrm{cu}(\mathrm{m})$ eredib(us) $\mathrm{n}$ (ost)ris promittimus. Quod si hec $\|$ om(n)i<a> ut superius leguntur non observa || \{va\}verimus vel adinpleverimus nos $\mathrm{n}$ (ost)ros || que eredib(us) vel successorib(us) quod siamus $\| \mathrm{co}(\mathrm{m})$ posituri et daturi Luponi $\mathrm{p}$ (res)b(ite)ri et in suis || successorib(us) que predicta eccl(esi)a ministra || ri debet papiensis monete solidos $C$ per || unu(m)que(m)q(ue) qui hoc non vult observare || nomine pene et insuper abeat meledic || tione ab om(n)ipotenti Deo quia ita deb(et) || abere quia nulli homini laici est || ecclesia in sua potestate et habe || at portione $\mathrm{cu}(\mathrm{m})$ diabolo et luda et Py | | lato et Sumone Macho, et soluta pena || hunc contractu(m) quod te ${ }^{83}$ nos sponte ${ }^{84} \mid$ | fieri rogavimus maneat ratusque II fieri rogavimus.

+ Litulfus KinKonis qu(on)da(m) filius rogatus s(ub)s(cripsi).

+Berardus Leonis (qu(on)da(m) filius rogatus s(ub)s(cripsi).

+ Petrus Liutulfi quondam filius rogatus s(ub)s(cripsi).

+ Adenulfus Peronis rogatus testes sum.

+ Petrus lozo rogatus testes sum.

+ Ego Benencasa $D(e) i$ nutu interve || nie\{nie\}nte notarius et advocatus, post roboratione $<m>o m(n) i u(m)||$ testiu( $m), c(o m)$ ple || bit et absolbit.

Seconda epigrafe apposta alla destra della facciata della chiesa di S. Stefano.

\section{Breve recordationis}

Il prete Lupo, anche a nome dei suoi successori presbiteri vel diaconi vel clerici,

\footnotetext{
82 eilius

${ }^{83}$ Quod te di incerta lettura

${ }^{84}$ Nosponte
} 
si impegna con stipulatione subnixa nei confronti dei fratelli Pepo e Bernardo, figli del fu Falcone; dei fratelli Litaldo, Gualfredo e Bernardo, figli del fu Rapizone; di Guido e Tebaldo, figli del fu Crescienzio e di Pepone, figlio del fu Farulfo, qui in nostra cartula nuncupantur, in conformità con la sacra lex, a non fare alcun conctractus con qualunque monastero, canonica, vescovo o abate, riguardante la chiesa di Santo Stefano costruita nel territorio del castrum di Collescipoli, la quale dovrà rimanere libera. I suddetti laici dal canto loro, essendosi obbligati con vicendevole stipulatione, non avranno alcun potere di agire nei confronti della chiesa. In caso d'inadempienza del prete lupo si stabilisce la sanzione di dieci lire di moneta pavese; nel caso l'inadempienza dovesse essere imputata ai suoi successori la sanzione non viene prevista dal momento che l'inadempiente, dovrà rispondere del suo operato dinanzi un vescovo religiosus ordinato secondo i canoni o dinanzi dei chierici religiosissimi del territorio di Collescipoli o di altro territorio, e ove non sia in grado di discolparsi sarà espulso dalla chiesa e le persone suddette dovranno eleggere un altro ministrator. II prete Lupo e i suoi successori avranno, infine, la facoltà di stipulare contratti di enfiteusi, o di altro tipo, a meliorationes economica della chiesa.

+ In no(min)e D(omi)ni [ab] incarnatione D(omi)ni n[(ost)ri lesu] || Christi sunt anni mill(esi)mo nonagesimo te[r(tio] II Henrico quonda(m) Henrici imper(at) $\mathrm{o}(\mathrm{r}$ )is filio || XII Kal(endas) mar(tii) indic(tione) II. Facio breve record[a] || tionis ego Lupo $p($ res $) b($ ite) $r$ tibi Peponi quonda $(m)$ filio || Falconis et Berardo fratri tuo et in om(n)ib(us) || aliis in Litaldo et Gualfredo et Berardo || et Tebaldo et Guidoni Crescentii et Peponi Far(ul)f(i) || qui in n(ost)ra cartula nuncupantur una cum || om(n)ib(us) meis successorib(us) p(res)b(ite)ri vel diaconi || vel cler(ici) facio ego stipulatione $(m)$ et hoc est: || de predicta eccl(esi)a s(an)c(t)i Stephani que hedifi || cata est infra pertinentia Collesci || puli quod ego neq(ue) de meis successoribus || non abeamus potestate $(\mathrm{m})$ de predicta ec || cl(esi)a nu(m) qua $(\mathrm{m})$ facere alique $(\mathrm{m}) \mathrm{c}(\mathrm{on}) \operatorname{tractu}(\mathrm{m})$ in nullo monasterio vel canonica aut in manu || episcopi v(e)I abb(at)is v(e)I ipsius success[or]ibu(s) || sicuti sacra lex precipit ut predic || ta ec || cl(esi)a semper permaneat in sua libertate $\mathrm{cu}(\mathrm{m})$ om(n)ib(us) suis ministratorib(us) || q(ui)a ita debet e(sse) ista stipulatione interve || niente a parte ministratorum set alia || stipulatio interveniens a $p(r e)$ dicti lai || cis qui superius nuncupatur quod nul || la potestate sit in eis de $p(r e)$ dicta eccl(esi)a || aut de suis reb(us) facere aliquid invito eis || ministratorib(us)

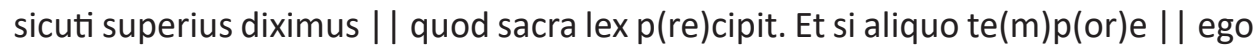
Lupo $p($ res)b(ite)r insurrexero quod $p$ (re)dicta scriptura infring(er)e audeo sicut stipu || latus sum quod siamus c(om)posituru(m) et datu || ru(m) in p(re)dicta eccl(esi)a papiensis monete libras || X quod si aliquis ex successorib(us) meis || hec supradicta infringere voluerit per || que me daturu[m] hanc pena $(\mathrm{m})$ obligavi non in e || ade $(\mathrm{m})$ pena( $\mathrm{m}$ ) esse volumus set o(mne)s insimul conventionem || fecimus ut coram religioso ep(iscop)o et canonica ordinato vel || si ep(iscopu)s 
non fu(er)it talis cora(m) reli

giosissimis istius vel alteri || us terre clericis $s(e) c(u n) d(u) m$ cano || nes si se excusare non potue || rit ab eade $(m)$ ec || clesia expellatur et aliu(m) ministratore $(\mathrm{m})$ fiat elec || tu a predictis personis in pre || dicta eccl(esi)a. || Et si ego Lupo $p$ (res)b(ite)r aut de meis successorib(us) || in aliquo $t$ (em)p(or) e volumus fac(er)e ||Henphiteosyn contractus || in aliqua persona vel aliut || contractu ut melioratio || fiat eccl(esi)e quod ide $(\mathrm{m})$ sit || potestatem in eis $\mathrm{s}(\mathrm{e})$ $c(u n) d(u m)$ mo || res alioru(m) ministrato rum || eccl(esi)e et hunc contractu(m) II semper permaneat ratus.

+Liutulfus Kinconis quon || da(m) filius scribere rogavi.

+Berardus Leonis quondam || filius scribere rogavi.

+ Petrus Liutulfi quondam || filius scribere rogavi.

+Adenulfus Petronis quon || da $(\mathrm{m})$ filius scribere rogavi.

+Petrus Zozo scrib(er)e rogavi.

+Ego Bene(n)Kasa Dei nutu || interveniente notari || us et advocatus con || plebit et absolbit.

Milj, 1800, pp. 83-85, 151-153; Angelelli, 1995, pp. 91-99; Angelelli, 1997, pp. 139-159; Guerrini, 2010. 


\section{Bibliografia}

Angelelli C., 1995: L’iscrizione della chiesa di S. Stefano di Collescipoli, in "Memoria Storica. Rivista del centro Studi Storici di Terni", 6, pp. 91-99

Angelelli C., 1997: La chiesa di S. Stefano di Collescipoli: un caso di reimpiego, in "Bollettino della deputazione di storia patria per l'Umbria", 94, pp. 139-159

Ansani M., 2006-2007: Appunti sui "brevia" di XI e XII secolo, in "ScrineumRivista", 4, pp. 109-154; anche in formato digitale in http://scrineum.unipv.it/ rivista/4-2007/ansani-brevia.pdf

Ansani M., 2011: "Caritatis negocia" e fabbriche di falsi. Strategie, imposture, dispute documentarie a Pavia fra XI e XII secolo, Roma, Isime (Nuovi studi storici, 90), pp. 15-53

Banti O., 1992: Epigrafi "documentarie" "chartae lapidariae" e documenti (in senso proprio). Note di epigrafia e di diplomatica medievali, in "Studi medievali", 3s., XXXIII, 1, pp. 229-242

Barbieri E., 1990: Notariato e documento notarile a Pavia (secoli XI-XIV), Firenze, La Nuova Italia (Pubblicazioni della Facoltà di Lettere e Filosofia dell'Università di Pavia, 58)

Bartoli Langeli A., 2003: Sui brevi italiani altomedievali, in "Bullettino dell'Istituto storico italiano per il Medio Evo", 105, pp. 1-23

Bartoli Langeli A., 2006: Notai, Scrivere documenti nell'Italia medievale, Roma, Viella

Bascapé C.G., 1936: Le vie dei pellegrinaggi medioevali attraverso le Alpi Centrali e la pianura lombarda, in "Archivio storico della Svizzera Italiana", XI, pp. 129169

Benati A., 1997: La chiesa di Bologna nell'Alto Medioevo, in Prodi, L. Paolini (edd.), Storia della Chiesa di Bologna, I-II, Bergamo, Edizioni Bolis, I, pp. 7-96

Bertelli G., 1985: Le Diocesi di Amelia, Narni e Otricoli, Spoleto, Cisam, 1985 (Corpus della scultura altomedievale, XII)

Bertolini C., 1905: Appunti didattici di Diritto Romano, Torino, Tipografia P. Gerbone, fasc. 1, pp.6-143

Bonfante P., 1932: Istituzioni di Diritto Romano, Milano, ed. F. Vallardi

Bottazzi M., 2006: Tra Papato e Impero: I'uso dell'epigrafia nei secoli XI e XII a Viterbo, in "Studi medievali", Ser. 3a, XLVII, pp. 305-360

Bottazzi M., 2012a: Italia medievale epigrafica. L'alto medioevo attraverso le scritture incise (secc. IX-XI), Trieste, Cerm

Bottazzi M., 2012b: Ancora sulle epigrafi di Collescipoli del 1094. Per una storia delle "chartae lapidariae", in "Bollettino della Deputazione di storia patria per I'Umbria", CIX, fasc. I-II, II, pp. 501-522 
Bougard F., 1995: La justice dans le royaume d'Italie de la fin du VIlle siècle au debut du XIe siècle, Rome, École française de Rome (Béfar, 291)

Bressan E., 1981: L'“Hospitale" e i poveri. La storiografia sull'assistenza: L'Italia e il "caso lombardo", Milano, Ned

Buonopane A., 2009: Manuale di epigrafia latina, Roma, Carocci editore

Cammarosano P., 2001a: Storia dell'Italia medievale. Dal VI all'XI secolo, Bari, Laterza

Cammarosano P., 2001b: Ėlites laiche e fondazioni religiose a Siena nel secolo XI, in M. Ascheri (ed.), La chiesa di San Pietro alla Magione nel Terzo di Camollia a Siena; il monumento, l'arte, la storia, Siena, Ed. Cantagalli, pp. 1-6

Campana A., 1984: la testimonianza delle iscrizioni, in Lanfranco e Wiligelmo. II Duomo di Modena, Modena, Ed. Panini

Capasso B., 2008: Monumenta ad Napolitani Ducatus Historiam Pertinentia. Riedizione ampliata, corretta e aggiornata con premessa e indice analitico di nomi di persona, di luogo e di cose notevoli, tomi I-III

Carosi A., 1986: Le epigrafi medievali di Viterbo (sec. VI- XV), Viterbo, Consorzio per la gestione delle Biblioteche Comunali degli Ardenti e Provinciale A. Anselmi

De Lasala F., S.I., Rabikauskas P., S.I., 2003: Il documento medievale e moderno. Panorama storico della diplomatica generale e pontificia, Roma, Editrice Pontificia Università Gregoriana, Istituto Portoghese di Sant'Antonio

De Luca A., 1979: La circolazione monetaria nel territorio di Spoleto nel secolo XII, in Palegraphica diplomatica et archivistica. Studi in onore di Giulio Battelli, II, Roma, Edizione di Storia e Letteratura (Raccolta di studi e testi, 140), pp. 183-209

Fantuzzi M., 1802-1804: Monumenti ravennati de' secoli di mezzo per la maggior parte inediti, 6 voll., Venezia, Tip. F. Andreola

Forcella V., 1889-1893: Iscrizioni delle chiese e degli altri edifici di Milano dal secolo VIII ai giorni nostri, I-XII, Milano, Prato ed.

Frezza P., 1974=2000: L'influsso del diritto romano giustineaneo nelle formule $e$ nella prassi in Italia, in Ius romanum Medii Aevi, Auspice Collegio Antiqui luris Studiis Provehendis - Société d'Histoire des Droits de l'Antiquité, pars I/2, Milano, 1974, pp. 3-108, oggi anche in F. Amarelli, E. Germino (edd.), Scritti, I-III, III, Romae, Pontificia Universitas Lateranensis Mursia, 2000 (Studia et documenta. Sectio luris Romani et Historiae luris, 4), pp. 3-108

Fumagalli A., 1802: Delle istituzioni diplomatiche, voll. I-II

Ghignoli A., 2004: Istituzioni ecclesiastiche e documentazione nei secoli VIII-XI. Appunti per una prospettiva, in "Archivio Storico Italiano", CLXII pp. 619-665

Giorgi I., Balzani U., 1879-1914: /l Regesto di Farfa compilato da Gregorio di Catino, 5 voll., Roma, (Biblioteca della S.R.S.P.)

Giulini G., 1855-1857: Memorie spettanti alla storia, al governo ed alla descrizione 
della città e campagna di Milano, I-X, Milano, Francesco Colombo Editore Librerie

Goetz E., Goetz W. (edd.), 1998: Die Urkunden und Briefe der Markgräfin Mathilde von (MGH), Laienfürsten- und Dynasten- Urkunden der Kaiserzeit, II

Grossi P., 1957: Le abbazie benedettine nell'alto medioevo italiano. Struttura giuridica, amministrazione e giurisdizione, Firenze, F. Le Monnier Editore

Guerrini G., 2010: Umbria - Terni, Spoleto, Centro italiano di studi sull'Alto Medioevo (Cisam) (Inscriptiones Medii Aevi Italiae saec. VI-XII, collana diretta da Cavallo e Ermini Pani, 2)

Hagemann W., 1974: L'archivio Capitolare di Narni e le sue pergamene fino al 1272, in "Bollettino della Deputazione di Storia Patria per I'Umbria", LXXI/2, pp. 1-45

lacomelli F., 1997: Dalle donazioni "pro anima" del secolo VIII ai testamenti del secolo XIII, in "Bullettino storico pistoiese" anno XCIX, III s. XXXII, pp. 79-95

Kuttner S., 1980: Urban II and the Doctrine of Interpretation: a turning Point, in S. Kuttner, The History of Ideas and Doctrines of Canon Law in the Middle Ages, London, Variorum Reprints, 1980, pp. 69-76

Latuada S., 1737-1738: Descrizione di Milano ornata con molti disegni in rame delle fabbriche più cospicue, che si trovano in questa metropoli raccolta ed ordinata da Serviliano Latuada, Milano, Giuseppe Cairoli mercante di libri, voll. I-V

Leicht P.S., 1933: I/ diritto privato preirneriano, Nicola Zanichelli Editore

Liva A.: 1979, Notariato e documento notarile a Milano. Dall'Alto Medioevo alla fine del Settecento, Roma, Consiglio Nazionale del Notariato

Lucioni A., 2006: Somma e la sua pieve, dall'alto Medioevo all'età borromaica, in La Basilica di S. Agnese. L'antica prepositurale di Somma e la sua pieve: storia, arte e architettura, Varese, Edizioni Lativa, 35-77

Lucioni A., 2011: Anselmo IV da Bovisio arcivescovo di Milano (1097-1101). Episcopato e società urbana sul finire dell'XI secolo, Milano, Vita e Pensiero

Manaresi C., 1937: Spirito dei tempi nuovi nei documenti privati lombardi del periodo precomunale, in "Atti e memorie del I Congresso Storico Lombardo" (Como, 21- 22 maggio, Varese, 1936), Milano, pp. 77-85

Manaresi C., Santoro C., 1969: Atti privati milanesi e comaschi del secolo XI, IV, Milano, Hoepli

Marrocchi M., 2008: "Abere non potuero neque carta neque breve" (Cda 242) Prime considerazioni sui "brevia" nella cultura giuridica e non giuridica delle scritture amiatine (secc. IX-XII), in "Bullettino Senese di Storia Patria", CXV, pp. 9-42

Matzke M., 2002: Daiberto di Pisa. Tra Pisa, Papato e prima crociata, Pisa, Ed. Pacini 
Milj E.A., 1800: Carsoli rediviva ovvero storiche ricerche intorno all'antichissima città di Carsoli nell'Umbria, Macerata, Stamperia di A. Cortesi

Minieri Riccio C., 1846: Cenni storici sulla distrutta città di Cuma ed altri opericoli Napoli, Tipografia V. Priggiobba

Nicolaj G., 1996: II documento privato italiano nell'alto medioevo, in Libri e documenti d'Italia: dai Longobardi alla rinascita delle città, C. Scalon (ed.), Atti del Convegno Nazionale dell'Associazione Italiana Paleografi e Diplomatisti, Cividale 5-7 ottobre 1994, Udine (Libri e Biblioteche, 4), 153-198; distribuito anche in formato digitale da "Scrineum"

Nicolaj G., 2007: Lezioni di Diplomatica generale. I: Istituzioni, Roma, Bulzoni Editore

Padoa Schioppa A., 1989: Aspetti della giustizia milanese dal secolo X al XII secolo, in Atti dell' $11^{\circ}$ Congresso internazionale di studi sull'alto medioevo, Milano, 2630 ottobre 1987, I-II, Spoleto, Cisam, I, pp. 459-549

Paoli C., 1942: Diplomatica, Firenze, F. Le Monnier Editore

Petrella E.D., 1911: I "Signa Tabellionatus" di S. Maria Nuova in Roma, in "Rivista storica benedettina", VI, pp. 337-365

Rolker C., 2010: Canon Law and the Letters of Ivo the Chartres, Cambridge, Cambridge University Press

Santoni F., 2009: /l documento privato di area romanica in età carolingia, in P. Erhart, K. Heidecker, B. Zeller (edd.), Die Privaturkunden der Karolingerzeit, Dietikon-Zürich, Urs Graf Verlag, pp. 73-83

Savioli L.V., 1784: Annali bolognesi, 1/2, Bassano, Remondini Giuseppe e figli

Sella P., 1928: Decreti lapidari dei secoli XII-XIII, in "Studi medievali", n.s., 1, pp. 406-421

Sergi G., 1994: L'aristocrazia della preghiera. Politica e scelte religiose nel medioevo italiano, Roma, Donzelli

Signorelli G., 1907: Viterbo nella Storia della Chiesa, voll. I-III, I, Viterbo, Tipografia Cionfi

Silvagni A., 1944: Monumenta epigraphica cristiana saeculo XIII antiquiora quae in Italiae finibus adhuc exstant edita, I-IV, fasc. II Mediolanum, tav. VI, fig. 6, In Civitate Vaticana, Pontificum Institutum Archeologiae Christianae

Sommerlechner A., 2010: Quellen zu oberitalischen Spitalern vom 11. bis Beginn des 14. Jahrhunderts, in Quellen zur europaeisches Spitalgeschichte in Mittelalter und Fhrüer Neuzeit, Wien: Bohlau - Munchen: Oldenbourg, pp. 165-208

Tjäder J.-O., 1954-1955: Die nichtliterarischen Papyri Italiens aus der Zeit 445700, Lund, CWK Gleerup, 1954-1955 - Stockholm, Skrifter utgivna av Svenska Institutet i Rom

Toubert P., 1973 : Les structures du Latium médiéval. Le Latium méridional et la 
Sabine du IXe à la fin du XIle siècle, I-II, Rome, École française de Rome (Béfar, 221)

Violante C., 1962a: Per lo studio dei prestiti dissimulati in territorio milanese (sec. X-XI), in Studi in onore di Amintore Fanfani, Milano, Giuffrè, pp. 641-735

Violante C., 1962b: Le prêts sur gage foncier dans la vie économique et sociale de Milan au XIe siècle, in "Cahiers de civilisation médiévale", V, pp. 147-168

Violante C., 1972: II monachesimo cluniacense di fronte al mondo politico ed ecclesiastico. Secoli X e XI, in P. Zerbi (ed.), Studi sulla cristianità medioevale. Società istituzioni spiritualità, Milano, Vita e Pensiero, pp. 3-67

Vismara G., 1988: Scritti di storia giuridica, 6. Le successioni ereditarie, Milano, Giuffrè editore

Zagni L., 2003: Carta, breve, libello nella documentazione milanese dei secoli XI e $X I I$, in D. Puncuh (ed.), Studi in memoria di Giorgio Costamagna (1916-2000), Genova (Atti della Società Ligure di Storia Patria, n.s. XLIII/1), 1073-1091

\section{Sitografia}

Codice diplomatico medievale lombardo:

Archivio di S. Maria al Monte Velate edito da P. Merati:

http://cdlm.unipv.it/edizioni/mi/velate-smaria1/carte/smmonte1017-08-00a, 19, Breve<conventionis> <ante 1017 agosto>

http://cdlm.unipv.it/edizioni/mi/velate-smaria1/carte/smmonte1017-08-00b, 20, Carta promissionis, 1017 agosto, <in domo Brela>

http://cdlm.unipv.it/edizioni/mi/velate-smaria1/carte/smmonte1081-02-00a, 50, Carta venditionis, 1081, febbraio, Bobbiate

http://cdlm.unipv.it/edizioni/mi/velate-smaria1/carte/smmonte1081-02-00b,

51, Breve recordationis, 1081, febbraio, Bobbiate

Archivio di S. Maria di Morimondo edito da M. Ansani:

http://cdlm.unipv.it/edizioni/mi/morimondo-smaria1/carte/morimondo109303-05a, 20, Carta venditionis, 1093 marzo 5, Milano

http://cdlm.unipv.it/edizioni/mi/morimondo-smaria1/carte/morimondo109303-05b, 21, Carta promissionis, 1093 marzo 5, Milano

http://cdlm.unipv.it/edizioni/mi/morimondo-smaria1/carte/morimondo109303-05c, 22, Notitia ad futuram tenendam memoriam et securitatem, 1093 marzo 5, Milano

http://cdlm.unipv.it/edizioni/mi/morimondo-smaria1/carte/morim1098-0708a, 29 Libellus, 1098 luglio 8, Pavia

http://cdlm.unipv.it/edizioni/mi/morimondo-smaria1/carte/morim1098-0708b, 30, Breve investiture et refutationis, 1098 luglio 8, Pavia 
